Atmos. Chem. Phys., 13, 3271-3305, 2013

www.atmos-chem-phys.net/13/3271/2013/

doi:10.5194/acp-13-3271-2013

(C) Author(s) 2013. CC Attribution 3.0 License.

\title{
The role of the global cryosphere in the fate of organic contaminants
}

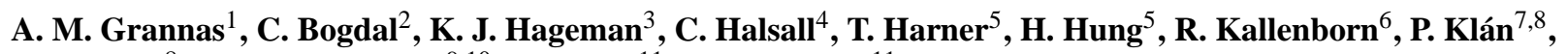 \\ J. Klánová ${ }^{8}$, R. W. Macdonald ${ }^{9,10}$, T. Meyer ${ }^{11}$, and F. Wania ${ }^{11}$ \\ ${ }^{1}$ Department of Chemistry, Villanova University, Villanova, PA 19085, USA \\ ${ }^{2}$ Institute for Chemical and Bioengineering, ETH Zurich, Wolfgang-Pauli-Strasse 10, 8093 Zürich, Switzerland \\ ${ }^{3}$ Department of Chemistry, University of Otago, Dunedin, 9010 New Zealand \\ ${ }^{4}$ Lancaster Environment Centre, Centre for Chemicals Management, Lancaster University, Lancaster LA1 4YQ, UK \\ ${ }^{5}$ Environment Canada, Science and Technology Branch, Toronto, Ontario M3H 5T4, Canada \\ ${ }^{6}$ Department of Chemistry, Biotechnology and Food Science, Norwegian University of Life Sciences, Christian Magnus \\ Falsen vei 1, Postbox 5003, 1432, Norway \\ ${ }^{7}$ Department of Chemistry, Faculty of Science, Masaryk University, Kamenice 5, 62500 Brno, Czech Republic \\ ${ }^{8}$ RECETOX, Faculty of Science, Masaryk University, Kamenice 3, 62500 Brno, Czech Republic \\ ${ }^{9}$ Department of Environment and Geography, Centre for Earth Observation Science, University of Manitoba, Winnipeg, \\ Manitoba R3T 2N2, Canada \\ ${ }^{10}$ Fisheries and Oceans Canada, Institute of Ocean Sciences, Sidney, British Columbia V8L 4B2, Canada \\ ${ }^{11}$ Department of Physical and Environmental Sciences, University of Toronto Scarborough, 1265 Military Trail, Toronto, ON \\ M1C 1A4, Canada
}

Correspondence to: A. M. Grannas (amanda.grannas@ villanova.edu)

Received: 26 June 2012 - Published in Atmos. Chem. Phys. Discuss.: 10 July 2012

Revised: 19 February 2013 - Accepted: 22 February 2013 - Published: 20 March 2013

\begin{abstract}
The cryosphere is an important component of global organic contaminant cycles. Snow is an efficient scavenger of atmospheric organic pollutants while a seasonal snowpack, sea ice, glaciers and ice caps are contaminant reservoirs on time scales ranging from days to millennia. Important physical and chemical processes occurring in the various cryospheric compartments impact contaminant cycling and fate. A variety of interactions and feedbacks also occur within the cryospheric system, most of which are susceptible to perturbations due to climate change. In this article, we review the current state of knowledge regarding the transport and processing of organic contaminants in the global cryosphere with an emphasis on the role of a changing climate. Given the complexity of contaminant interactions with the cryosphere and limitations on resources and research capacity, interdisciplinary research and extended collaborations are essential to close identified knowledge gaps and to improve our understanding of contaminant fate under a changing climate.
\end{abstract}

\section{Introduction}

It is now widely recognized that organic contaminants are globally distributed and may pose a severe risk to wildlife and human health (AMAP, 2009a). The global transport of contaminants has been well documented and characterized (Wania et al., 1998a; Finizio et al., 1998; Bard, 1999; Wania, 2003; Gouin et al., 2004; Harner et al., 2006; Scheringer, 2009). Contaminants accumulate in polar regions and mountains, due to global and local coldtrapping, far from their original point of use (Wania and Mackay, 1993; Blais et al., 1998; Daly and Wania, 2005; Wania and Westgate, 2008). The observation of elevated concentrations of organic contaminants in polar and mountain areas far from contaminant source regions has led to much work aimed at characterizing the unique role of snow and ice in contaminant transport and fate during the last decade. A number of reviews discuss various aspects of the cryosphere in contaminant cycling (Wania et al., 1998b; Herbert et al., 2006), including contaminant interaction with seasonal snowpack (Halsall, 2004), photochemistry

Published by Copernicus Publications on behalf of the European Geosciences Union. 
in snow (Domine and Shepson, 2002; Grannas et al., 2007a), contaminant fate during snowmelt (Meyer and Wania, 2008), and changing contaminant/environment interactions with climate change (Couillard et al., 2008). While much recent work has focused on individual compartments within polar and mountain regions (e.g. snow, sea ice, glaciers) or the impact of contaminants on ecosystem health, this work has not yet been placed in the context of understanding the role of the global cryosphere in contaminant fate. Here we seek to synthesize the information available about specific elements of the cryosphere into a global picture of contaminant fate in cold environments.

The global cryosphere is defined as the part of the Earth's surface where water is present in solid form. It thus includes sea ice, lake ice, river ice, snow, glaciers, ice caps, ice sheets, ice shelves, and the frozen geosphere (permafrost). The cryosphere is present in high latitude, high altitude, boreal and mid-latitude (including urban) regions and is a vital component of the Earth system for several key reasons. First, the cryosphere plays a crucial role in the energy balance of the Earth via two main mechanisms - heat transport and albedo. Ice and snow present in polar regions contribute to the temperature gradient observed between the equator and the poles, which drives wind and ocean currents. Both atmospheric and ocean water currents transport heat toward the poles and maintains the temperature balance across the Earth. Ice also serves to insulate the ocean surface, preventing heat loss from the ocean to the atmosphere, which would result in atmospheric warming. Additionally, up to $90 \%$ of incident radiation is reflected by snow and ice, compared to the relatively low albedo of open ocean or vegetation. Thus, the melting of sea ice and snowpack results in a positive feedback cycle due to decreased albedo, increased ocean to atmosphere heat transfer, and hence further surface warming. This positive feedback results in accelerated loss of ice/snow under climate warming conditions (IPCC, 2007). Observations show that the pace of ice sheet/ice cap loss is increasing (Serreze et al., 2007), and September 2012 saw the lowest Arctic sea ice extent recorded to date (NOAA, 2012), surpassing the record-breaking sea ice loss recorded in 2007 (Stroeve et al., 2007).

Additionally, the cryosphere is a critical component of the global water cycle. Ice sheets hold nearly $75 \%$ of the world's freshwater (IPCC, 2007), and regional variations in mountain snowpack, glaciers or small ice caps will play an important role in freshwater availability. Finally, it has been shown that snow and ice can play an important role in atmospheric chemistry processes (Grannas et al., 2007a), serving as a source of reactive species to the atmosphere as well as an active surface upon which chemical reactions may take place.

With respect to organic contaminants (specifically persistent organic pollutants), cryospheric compartments may serve as reservoirs or may play a role in the active cycling of contaminants. Interaction of contaminants with snow and ice occur in a variety of ways, beginning with scavenging of atmospheric species by precipitation (Sect. 3.1). Post-depositional processes can then play a role in contaminant fate, via processes such as revolatilization (Sect. 3.2), snowmelt (Sect. 3.3), or snowpack photochemical processing (Sect. 3.9). Sea ice can entrain contaminants present in sediment, or uptake contaminants in the seawater which become entrapped with brine in the forming ice. Subsequent freezing-out concentrates the brine resulting in the enrichment of contaminants. Upward percolation of contaminantenriched brine may also occur into the snowpack overlying the ice. These sea ice processes are described in Sect. 3.5. Additionally, we refer the reader to associated recent review articles discussing the incorporation and chemistry of organics in environmental ices (McNeill et al., 2012); the role of ice and snow in halogen activation chemistry (Abbatt et al., 2012); and the relationship between snow microstructure and physical/chemical processes occurring in snow (BartelsRausch et al., 2012).

Cryospheric environments in polar regions on Earth are considered vital parts of regional ecosystems (McConnell, 2006; Slaymaker and Kelly, 2007), and contamination of these reservoirs may have significant negative impacts on ecosystem health. These negative effects may be influenced by climate change, as this will significantly impact the nature and extent of the cryosphere, in turn affecting cryospheric processes and properties. Arctic sea ice extent is decreasing at an alarming rate (Perovich, 2011; AMAP, 2011a), and glaciers, also now undergoing rapid wastage (Sharp et al., 2011; Hanna et al., 2011), may deliver previously stored contaminants to surrounding ecosystems (Sect. 3.4) (Blais et al., 2001a; Bogdal et al., 2010). Predicting the impact of climate change on contaminant fate within the cryosphere presents a great challenge. Not only is pollutant fate controlled by a wide range of physical and chemical properties of contaminants that are strongly temperature dependent, but the nature and extent of the cryosphere itself may be highly variable under different climate change scenarios. Contaminant cycles, as integrated parts of this complex environmental system of cold regions, are similarly prone to change as a result of a changing climate (Macdonald et al., 2000, 2003a, b, 2005; Hoffmann et al., 2012; Guglielmo et al., 2012). This review offers a perspective on the interactions between contaminants and the various cryospheric compartments at a range of latitudes and considers the potential impacts of climate-change in each compartment.

\section{Current policy and monitoring efforts}

The importance of the cryosphere in the context of organic contaminants and other hazardous chemicals is addressed at the international level through various treaties, agreements and programs. In many cases these policies recognize the uniqueness of polar or alpine regions where the cryosphere 
plays a key role in the cycling and fate of toxic chemicals and ultimately their delivery to the food chain, including humans. As new contaminants are included in reduction efforts, changing policies and monitoring priorities will in part dictate the measurement and process studies undertaken by the scientific community. Looking to the future, we can foresee the need for political engagement to address changes to these once-pristine regions that are associated with climate change and increased human activity including transport/shipping, industrial development, and mining of resources.

The Stockholm Convention on persistent organic pollutants (POPs) came into force in 2004 and is the largest international convention on POPs. Contaminants that have relatively long environmental lifetimes, that become widely geographically distributed, and that have bioaccumulative properties with adverse health impacts to humans or the ecosystem can be considered for inclusion. Parties to the convention are required to then take measures to eliminate or reduce the use and release of POPs into the environment. Such action has led to measureable environmental concentration decreases in, for example, polychlorinated biphenyls (PCBs), polybrominated diphenylethers (PBDEs), hexachlorocyclohexane isomers (HCHs) and dichlorodiphenyltrichloroethane (DDT) (UNEP, 2012). Table 1 details the current Stockholm Convention targets, along with references to literature describing the key physical-chemical properties of these pollutants where available. In many cases, data are available which allow for the derivation of internally consistent, environmentally-relevant physical-chemical properties at different temperatures, including cryospherically-relevant temperatures. However, for a number of chemicals, no thermodynamically consistent physical-chemical properties are available in the literature. Mackay et al. (2006) summarize measured physical-chemical properties with temperaturedependent parameters wherever available. For some chemicals, the entropy of fusion and enthalpies of vaporization, sublimation and fusion are provided, which would allow for the derivation of subcooled liquid properties and some temperature dependent physical-chemical properties. This reference also includes typical half-lives of pollutants for air, water, soil, sediment and biota where available. Toxicological measures of individual contaminants are more difficult to quantify, however. Acute effects are often quantified by $\mathrm{LD}_{50}$ (the dose at which $50 \%$ of a population experiences a lethal effect), however most POPs are of concern due to the potential effects of chronic exposure. These effects are often harder to quantify, and the potential synergistic effect of a variety of pollutants acting in concert is an area of increasing concern. The review of Escher and Hermens (2002) discusses mechanistic aspects of ecotoxicology and ecotoxicological risk assessment.

A key component of the Stockholm Convention is the Global Monitoring Plan (GMP) which addresses the needs of Article 16 of the Convention, dealing with measuring its effectiveness. The first global monitoring report target- ing POPs in air and human milk/blood was completed in 2009 and recognized the importance of the cryosphere on levels and trends of POPs in air, their cycling between the cryosphere and air, and re-release of previously trapped POPs from snow/ice due to climate change. The report also emphasized that monitoring data need to be integrated with multi-media models and emissions information to distinguish changes that are due to regulatory actions from changes associated with historical releases and chemical cycling (UNEP, 2009).

The POPs Protocol of the Convention on Long-Range Transboundary Air Pollution (CLRTAP), established in 1998 (UNECE, 1998), is complementary to the Stockholm Convention but addresses the concerns of countries within the United Nations Economic Commission for Europe region. Under the CLRTAP, monitoring is carried out through the European Monitoring and Evaluation Programme and work on emissions, transport, and fate modeling is carried out through The Meteorological Synthesizing Centre - East and several working groups, namely the Task Force on Measurements and Modeling, the Task Force on Integrated Assessment and Modeling and the Task Force on Hemispheric Transport of Air Pollutants. The 2010 POPs Assessment Report of the Task Force on Hemispheric Transport of Air Pollutants included monitoring results for POPs in the cryosphere and the important role of this compartment in modeling the fate and transport of POPs, including the delivery of POPs to the food chain (UNECE, 2010).

The Arctic Monitoring and Assessment Programme (AMAP) is an international organization of circumpolar countries established in 1991. POPs are one of several priority issues of AMAP. Results of Arctic monitoring and research are integrated in assessment reports to inform on the status of the Arctic environment. The latest assessment on POPs was published in 2009 (AMAP, 2009a) and a special report on "The Greenland Ice Sheet in a Changing Climate" (AMAP, 2009b) was prepared. The Canadian Northern Contaminants Program (NCP), which reports through AMAP, has been operating since the late 1980s. Some of the early work under NCP synthesized a wide variety of data collected by various Arctic programs into five reviews dealing with sources, occurrence, and pathways of contaminants (Barrie et al., 1992); marine ecosystem contamination (Muir et al., 1992); terrestrial ecosystem contamination (Thomas et al., 1992); freshwater contamination (Lockhart et al., 1992); and risks/benefits of northern diets (Kinloch et al., 1992).

The Antarctic Treaty entered into force in 1961. The purpose of the treaty is to protect the Antarctic environment from negative anthropogenic influence. Among other protective measures that have been adopted under this treaty, the Protocol on Environmental Protection, adopted in 1991, commits Parties to the comprehensive protection of the Antarctic environment and prohibits all activities relating to Antarctic mineral resources, except for scientific research. The Scientific Committee on Antarctic Research has recently 
Table 1. Stockholm Convention Persistent Organic Pollutants, Uses, and References for Key Chemical Properties Relevant to the Cryosphere.

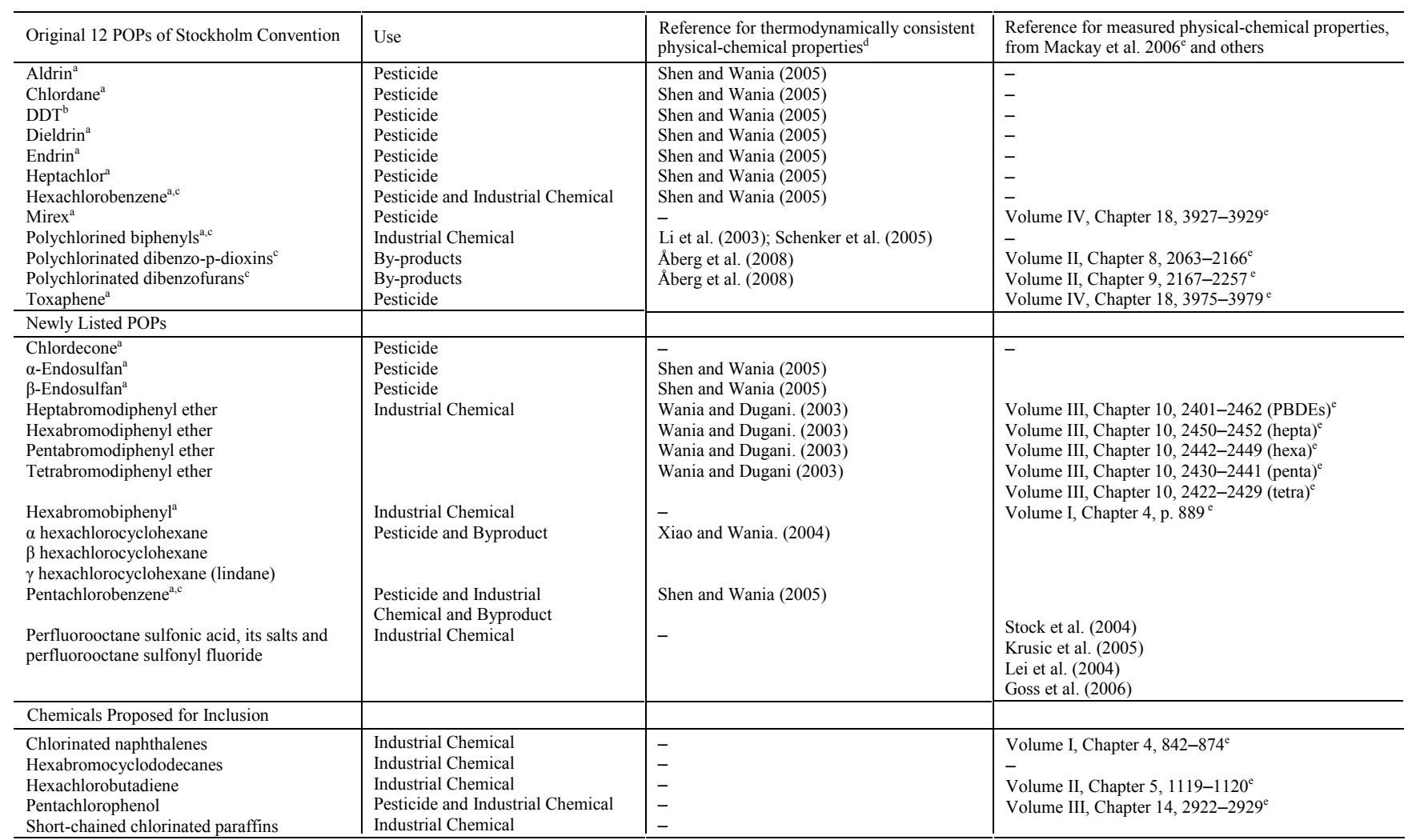

a Annex A species: convention parties must take measures to eliminate the production and use of the chemicals listed under Annex A. Specific exemptions for use or production are listed in the Annex and apply only to Parties that register for them.

b Annex B species: convention parties must take measures to restrict the production and use of the chemicals listed under Annex B in light of any applicable acceptable purposes and/or specific exemptions listed in the Annex.

${ }^{c}$ Annex C species: convention parties must take measures to reduce the unintentional releases of chemicals listed under Annex $\mathrm{C}$ with the goal of continuing minimization and, where feasible, ultimate elimination.

${ }^{\mathrm{d}}$ For these chemicals, references are given which allow for the derivation of internally consistent environmentally-relevant physical-chemical properties at different temperatures, including cryospherically-relevant temperatures.

e For these chemicals, no thermodynamically consistent physical-chemical properties are available in the literature. Mackay et al. (2006) report measured physical-chemical properties, including entropy of fusion and enthalpies, which should allow for the derivation of temperature dependent physical-chemical properties. This reference also includes typical half-lives of pollutants for air, water, soil, sediment and biota where available.

published a thorough report on Antarctic Climate Change (ACCE, 2009), which highlights changes to the cryosphere of this continent.

The sensitivity of alpine regions to organic contaminants is dealt with through a variety of regional and multinational programs, including the International Commission for the Protection of the Alps and the Alpine Convention and the International Scientific Committee on Research in the Alps (ISCAR). The Alpine Convention is an agreement within the law of nations for the overall protection and the sustainable development of the Alps, including pollution prevention, which came into force in 1995 and is signed by Austria, France, Germany, Italy, Liechtenstein, Switzerland, Slovenia and the EU. As defined in its mission statement, the International Scientific Committee on Research in the Alps (ISCAR) promotes international cooperation in Alpine research. In 2000, ISCAR was recognized by the Alpine Conference as an official observer of the Alpine Convention. In this func- tion, ISCAR provides research and scientific expertise in the official bodies of the Alpine Convention.

A number of global and regional long-term monitoring efforts have been established within the above mentioned treaties, agreements and programs to measure long-term changes in contaminant levels. With the list of contaminants expanding, future research and monitoring efforts will need to consider the cycling and fate of chemically diverse analytes. This will present sampling and analytical challenges. Process studies are critical to understanding the local, regional and global fate of historic and emerging contaminants. In Sect. 3, we discuss in more specific terms these processes and the role of the global cryosphere in contaminant transport, dynamics and variability. 


\section{Impacts of the cryosphere on contaminant fate}

Once emitted to the atmosphere, organic contaminants can undergo a variety of physical, chemical and biological processes that in combination determine their fate in the environment. Initially, semi-volatile organic contaminants reach high latitudes predominantly via long-range atmospheric transport (LRAT), which has an associated time of transport of a week or less. For contaminants that have low air-water partition coefficients $\left(\log \mathrm{K}_{\mathrm{aw}}<-2\right.$ ), ocean transport may play a significant role (e.g., Wania, 2003). Ocean transport requires a longer time (years to decades) and therefore exhibits a considerable lag in the delivery to polar regions, but with time, and especially once the emissions have been controlled, this route may become the dominant transport pathway (e.g., in the case of beta-hexachlorocyclohexane; Li et al., 2002). When the sea water enters ice-covered regions, organic contaminants become protected from photolysis by low ambient light levels, and from microbial degradation by uniformly cold water (Pućko et al., 2012) with the result that they may persist long enough to transport to even the most remote locations.

LRAT is the main mechanism that results in the observed global distribution of contaminants (Peterle, 1969; Peel, 1975; Risebrough et al., 1976; Tanabe et al., 1983; Oehme and Mano, 1983; Oehme, 1991; Barrie et al., 1992, 1997, 1998) and numerous partitioning processes can occur along these atmospheric transport routes. Long-term atmospheric monitoring provides a critical activity to estimate spatial and temporal trends, and also to identify the manner in which climate change may affect atmospheric transport. In both Arctic and Antarctic regions long-term atmospheric monitoring programs are presently established (Su et al., 2008; Hung et al., 2010; Ma et al., 2011; Kallenborn et al., 2013). Specifically, in the Arctic, legacy POPs have been monitored for the past two decades, whereas in the Antarctic similar monitoring has been initiated more recently, commencing in 2007 (Kallenborn et al., 2013). Incorporation in snowpack and ice creates temporary reservoirs of contaminants, but as melting of the reservoirs progresses, redistribution occurs. The wide variety of processes that contribute to contaminant cycling and fate are summarized in Fig. 1, and discussed in further detail in Sects. 3.1-3.9.

\subsection{The role of snowfall in contaminant delivery to surfaces - contaminant scavenging by snow}

Snow precipitation is a crucial first-step in the delivery of contaminants from the atmosphere to Earth's surface and it plays an important role in the transport and ultimate distribution of organic contaminants in cold environments. There are several processes that incorporate organic contaminants in/onto snow (Fig. 2). Snow forms by the condensation of water vapor onto an ice-forming nucleus or when supercooled water droplets freeze onto the surface of growing ice crystals (riming) (Pruppacher and Klett, 1978). Nucleation scavenging occurs when contaminants are incorporated into the snowflake as part of the ice-forming nucleus or as part of the cloud condensation nuclei that nucleate supercooled water droplets. Particle-scavenging may occur during the riming process, or as a snowflake falls through the atmosphere, acting in essence as a particle filter (Wania et al., 1998b). Gas-phase species may also partition directly to the snowflake surface through adsorption processes (Bartels-Rausch, 2012). The enhanced partitioning of gasphase chemicals to the snow surface at cold temperatures, combined with the large surface areas of snowflakes, results in snow being an excellent scavenger of semi-volatile organic chemicals from the atmospheric gas phase (Lei and Wania, 2004; Domine et al., 2007a). The distribution of contaminants in the atmosphere (whether gas phase, particle bound, or associated with atmospheric aqueous phases), will be determined by the physicochemical properties of the chemical and is strongly temperature dependent.

Organic contaminants have been measured in freshly fallen snow collected in different parts of the world, including at an urban site in Europe (Czuczwa et al., 1988), in mid-latitude mountains (McConnell et al., 1998; Zabik and Seiber, 1993), in the Arctic (Herbert et al., 2005a, b), and in Antarctica (Cincinelli et al., 2005). Lab-based studies have measured the sorption of organic contaminants to snow and ice (Hoff et al., 1995; Roth et al., 2004; Domine et al., 2007a), models have been developed for estimating snow-air partition coefficients (Roth et al., 2004), and scavenging ratios have been determined for a number of volatile and semi-volatile organic compounds (Franz and Eisenreich, 1998; Starokozhev et al., 2009). The mechanism and degree of contaminant scavenging varies for different chemicals and at different temperatures, as shown for polycyclic aromatic hydrocarbons (PAHs) and PCBs via calculations for vapor and particle scavenging ratios (Wania et al., 1999a; Lei and Wania, 2004).

Organic contaminants may also enter snowpack by dry gaseous deposition and dry particle deposition (Fig. 2). The relative importance of these different scavenging and deposition pathways has been investigated via modeling (Daly and Wania, 2004; Stocker et al., 2007) and varies significantly between specific contaminants, depending on their physicochemical properties. Carrera et al. (2001) used field data to show that the importance of snowfall in delivering contaminants to remote alpine regions varied significantly between mountain regions in Europe. In a separate study, measurements showed that two thirds of the total deposition of polychlorinated dibenzo- $p$-dioxins and dibenzofurans (PCDD/Fs) to a Northern Swedish watershed occurred during months with average temperatures below freezing, with highest values observed during months with snowfall (Bergknut et al., 2011). It should be noted that in the case of water-soluble organic species, snow scavenging is actually less efficient than rain scavenging (Lei and Wania, 2004). By 


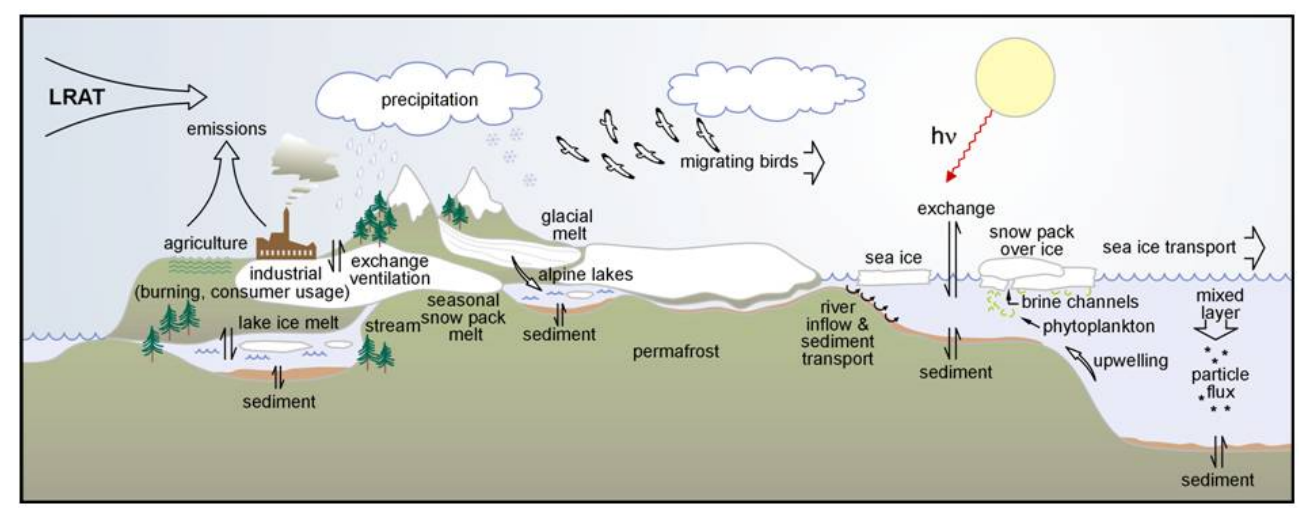

Fig. 1. Schematic diagram illustrating the various elements of and interactions occurring in the cryosphere that impact contaminant cycling and fate. LRAT (long-range atmospheric transport) is primarily responsible for the global distribution of contaminants, but the various exchanges represented here play important roles in cycling and redistribution of contaminants.

measuring pesticides in both summer rain and winter snowfall, Mast et al. (2007) showed that the total annual wet deposition of the relatively water-soluble pesticides, atrazine, carbaryl, and dacthal in the Rocky Mountains was $>85 \%$ from rain.

The degree to which contaminants are delivered from the atmosphere to the Earth's surfaces by falling snow depends not only on the contaminant concentrations in the falling snow (a function of scavenging efficiency) but also on the amount of snow that falls. Blais et al. (1998) showed that the increasing amounts of contaminant deposition along an elevational gradient in western Canada was due to both increasing contaminant concentrations in snow with elevation (due to the temperature effect) and increasing amounts of snowfall with elevation. Annual precipitation trends along elevational gradients vary significantly in different mountain systems (Wania and Westgate, 2008), which partly explains why contaminant concentration trends in mountains vary. In a different type of spatial comparison, Usenko et al. (2007) evaluated contaminant fluxes and lake sediment contaminant loads at two lakes on the west and east side of the Continental Divide in Colorado, US. They found that differences in sediment contaminant fluxes in these two lakes could be partially explained by differences in the snow flux and load of the contaminants on either side of the divide. Stocker et al. (2007) used a multimedia box model to investigate the influence of snow and ice on the global fate of seven specific contaminants with varying physicochemical properties. They found that in low latitudes, snow acts as a transfer medium, allowing for atmospheric uptake with subsequent release to water or soil during snowmelt. In high latitudes, snow and ice act as a barrier to deposition of contaminants to water, soil and vegetation. For example, in a model including snow and ice, the mass of chemicals in soil in high latitudes was found to be between $27 \%$ and $97 \%$ of the mass found in soil when no snow or ice cover was present in the model. Both modeling and measurement studies indicate that the importance of snowfall in affecting the transport behavior and distribution of organic contaminants in the environment depends heavily on chemical properties of the contaminant and geographic location (which affects temperature, snow physical properties and partitioning processes).

Because snow can serve as an efficient scavenger for semi-volatile organic contaminants, this mechanism of contaminant delivery to the surface is susceptible to changes due to climate change. Changing temperatures will affect the adsorption equilibria of contaminants on snow crystals, or the gas-particle distribution of a species in the atmosphere (which in turn could affect the uptake mechanism to a snow/ice crystal). In addition to changing the partitioning equilibria of contaminants between gas phase and snow and ice, changing temperature could influence contaminants in snow via a change in the extent or amount of snow precipitation (Macdonald et al., 2003a, b; Stocker et al., 2007). The Intergovernmental Panel on Climate Change (IPCC, 2007) projected that precipitation in a changing climate will differ considerably around the globe with increasing (e.g. $40 \%$ increase from mean) and decreasing (e.g. $20 \%$ reduction from mean) trends occurring in different regions. In regions with increased snow precipitation, deposition of organic contaminants from air to surface media would increase; and in regions with and during times of low or no precipitation, organic contaminants can be atmospherically transported more effectively (UNEP/AMAP, 2011). However, there is a lack of direct observational evidence of the effect of changing temperatures due to climate change on organic contaminant transport and fate. Changes in partitioning equilibria, snow physical properties, and changes to the timing and nature of snow metamorphism, aging, and compaction would all be influenced by climate change and could play a role in contaminant behavior in snow. This is certainly an area for future research and monitoring endeavors. 


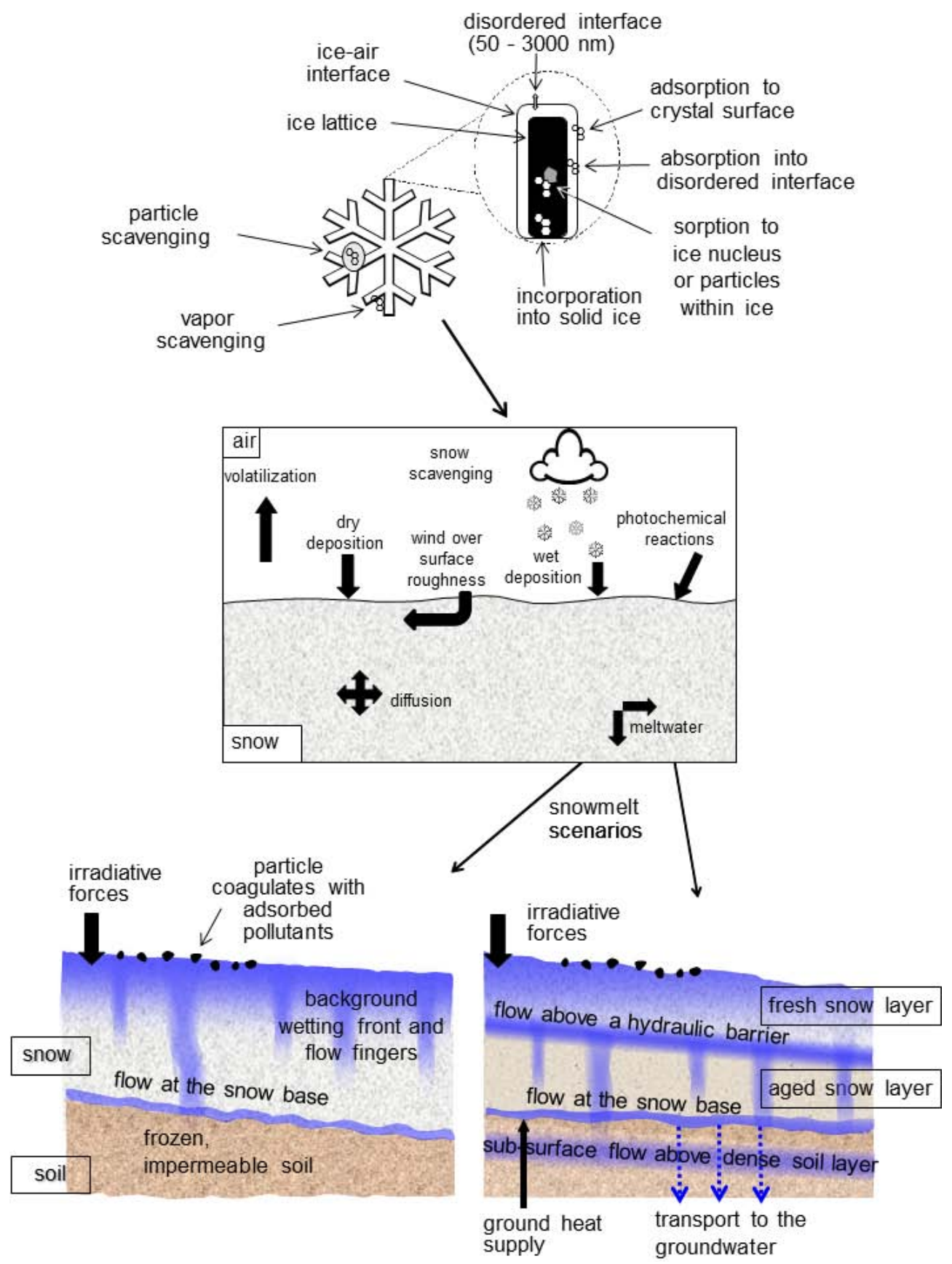

Fig. 2. Top illustration shows the various processes involved in organic contaminant partitioning to snow during deposition, including adsorption to the surface of the crystal, absorption into the disordered interface on the surface of the snow crystal, uptake into the solid-ice matrix or incorporation with the ice-forming nucleus or from particles present as a droplet freezes. Incorporation of contaminants may also occur by both vapor and particle scavenging. Middle illustration shows the various processes involved in cycling organic contaminants within a deposited snowpack, including deposition and revolatilization, wind-pumping (ventilation), photochemical reaction, and movement with meltwater. Bottom illustration shows two snowmelt scenarios, comparing a snowmelt process over soil typical of Arctic environments (left) where permafrost is present and in temperate environments (right) where hydraulic barriers are more prevalent and bottom-melt occurs due to the supply of heat from underlying ground. Figure adapted from Meyer and Wania (2008) and Herbert et al. (2006). 
3.2 The exchange of organic chemicals between snowpack and the atmosphere by wind ventilation

Once snow has been deposited to Earth's surface, it is by no means a static sink for atmospheric contaminant loads. The porous nature of snow as well as the extent of the global area that is permanently or seasonally covered by snow provides for a substantial exchange of organic chemicals between snow and the overlying atmosphere (Fig. 2) (Wania et al., 1998b; Halsall, 2004), which may even affect global atmospheric chemistry (Domine and Shepson, 2002; Grannas et al., 2007a). Emission of chemicals from the snowpack to the atmosphere may be driven thermodynamically by a loss of storage capacity in aging snow with diminishing surface area (Cabanes et al., 2003; Bartels-Rausch, 2012) and possibly higher temperature, and kinetically by wind ventilation (Colbeck, 1989; Clarke and Waddington, 1991; Albert and Shultz, 2002; Albert et al., 2002). Such loss has been observed empirically in the field (Herbert et al., 2005b; Finizio et al., 2006; Burniston et al., 2007) and also reproduced by simulation models (Daly and Wania, 2004; Hansen et al., 2006, Stocker et al., 2007). Even semi-volatile organic contaminants such as tri- and tetrachlorinated PCBs as well as three- and four-ring PAHs can volatilize from the snow in notable amounts (Meyer and Wania, 2011b). In such cases wind ventilation efficiently removes gaseous substance from the snow pore space (interstitial air), while the associated chemical loss in the interstitial air is rapidly compensated for by desorption from snow grain surfaces, in order to maintain partitioning equilibrium (Meyer and Wania, 2011b).

The gaseous mass transfer between snow and the atmosphere is in most cases limited by transport of the chemical within the interstitial air. The more a chemical partitions into the interstitial air, the larger is its potential for exchange with the atmosphere (Meyer and Wania, 2011b). Chemicals in dry snow are either present as gases in the interstitial air, or sorbed to snow grain surfaces and particulate matter. In dry and clean snow, prevalent in subarctic and arctic regions during winter, only the interstitial air and snow grain surfaces are important for mass transport (Meyer and Wania, 2011b). The distribution between those two phases depends on the chemical's partitioning properties, snowpack properties and temperature. Langmuir-type surface adsorption has been used to successfully describe the interaction of a variety of gases with frozen water surfaces, although deviations can occur (see Bartels-Rausch et al., 2012 for a detailed discussion). Roth et al. (2004) proposed use of a sorption coefficient to quantify semi-volatile organic compound interaction with snow. This temperature-dependent equilibrium sorption coefficient to the snow grain surface from the gas phase $K_{\text {IA }}$ [m] can be expressed as:

$K_{\mathrm{IA}}=C_{\mathrm{I}} / C_{\mathrm{A}}$,

where $C_{I}\left[\mathrm{~mol} \mathrm{~m}^{-2}\right]$ is the chemical concentration at the snow grain surface and $C_{\mathrm{A}}\left[\mathrm{mol} \mathrm{m}^{-3}\right]$ is the interstitial air concentration. The dimensionless bulk snow/air partition coefficient $K_{\mathrm{SA}}$ can be calculated using:

$K_{\mathrm{SA}}=K_{\mathrm{IA}} \mathrm{SSA} \rho$,

where SSA is the specific snow surface area $\left(\mathrm{m}^{2} \mathrm{~kg}^{-1}\right), \rho$ is the density of the snow $\left(\mathrm{kg} \mathrm{m}^{-3}\right)$ and $K_{\mathrm{IA}}(\mathrm{m})$ is calculated as in Eq. (1). Compared to subarctic snow, arctic snow usually exhibits higher densities and specific surface areas (Domine et al., 2007b, 2012), shallower depths (Sturm et al., 1995), and lower permeability (Albert and Shultz, 2002), and is exposed to higher wind speeds (Canadian Wind Energy Atlas, 2003) as well as lower temperatures (Taillandier et al., 2006). The latter results in a generally much higher $K_{\mathrm{SA}}$ in Arctic snow compared to subarctic snow. Roth et al. (2004) measured $K_{\mathrm{IA}}$ values for numerous organic chemicals and provided a linear free energy relationship that can be used to estimate the chemical partitioning into the gas phase for numerous organics. Domine et al. (2007a) compared their experimental results for phenanthrene adsorption to snow to the value calculated using the Roth et al. (2004) method and found reasonable agreement. Combining their experimental results with calculations, Domine et al. (2007a) determined that due to combined effects of temperature and snow SSA, in a subarctic snowpack $93 \%$ of phenanthrene would remain in the atmospheric boundary layer with $7 \%$ taken up by snowpack, while in the presence of an Arctic snowpack $22 \%$ of phenanthrene would be present in the atmospheric boundary layer with $78 \%$ taken up by snowpack adsorption processes. As such, Arctic snowpack could cause large seasonal variations in gas phase phenanthrene concentrations due to snowpack build up and melt; however, subarctic snowpack would have little influence on boundary layer phenanthrene concentrations. Similarly, Taillandier et al. (2006) concluded that subarctic snowpacks would take up less PCB-28 than Arctic snowpack. Specifically, only $6 \%$ of PCB-28 would exist in the boundary layer over an Arctic snowpack, whereas nearly $71 \%$ of PCB-28 would be in the atmospheric boundary layer over a subarctic snowpack. This was also confirmed in a case study by Meyer and Wania (2011b) which revealed that PCB-28 would experience a net release from a subarctic snowpack, whereas in the Arctic net deposition would occur. More recently, Domine et al. (2012) found that the Barrow, Alaska snowpack would trap most of both PCB-180 (a relatively low volatility compound, with 7 chlorine atoms) and PCB-28 (a high volatility compound, with 3 chlorine atoms), due to the low temperature and high surface area available. Roth et al. (2004) discuss that temporal and spatial snow variability as well as the influence of particles needs to be investigated in order to derive more general statements on sorption properties of snow, however.

In previous studies that describe snow-atmosphere exchange of contaminants, the chemical flux has been calculated as the product of the concentration difference between the air above the snow and the snow interstitial air, and an overall mass transfer coefficient (MTC). The MTC term is 
most appropriately used to describe contaminant mass transport between the snowpack and the atmospheric layer adjacent to the snowpack surface. To adequately describe mass transfer into the atmospheric boundary layer, additionally requires taking into account atmospheric eddy diffusivity (which is a function of atmospheric stability). Both MTC and atmospheric stability can be highly variable and are associated with relatively high uncertainty. For example, eddy diffusivities can be much lower in Arctic regions (compared to mid-latitude regions) due to often weak and intermittent turbulence observed under stable atmospheric conditions (Guimbaud et al., 2002). In some studies the MTC was set as a constant (Wania, 1997; Halsall, 2004; Herbert et al., 2006; Stocker et al., 2007), whereas in other studies it was treated as a wind speed-dependent variable (Daly and Wania, 2004; Hansen et al., 2006). Such parameterizations should be appropriate when investigating chemical exchange processes over time periods of weeks or months. However, the description of processes occurring on shorter time scales, such as the diurnal chemical exchange induced by photolytic reactions, requires a more precise parameterization. Albert and Shultz (2002), Albert and Hawley (2002) and Albert et al. (2002) filled some of the associated knowledge gap by investigating chemical transport within snow induced by wind ventilation. Wind ventilation was found to substantially enhance the snow-atmosphere exchange and can cause advective chemical transport even at snow depths of several meters (Albert et al., 2002). The intensity of wind ventilation depends on the wind speed, snow permeability and snow surface roughness features. Wind ventilation in snow is caused by pressure variations induced by wind turbulence and "form drag" pressure around snow surface roughness features (Albert and Hawley, 2002). For example, at Summit, Greenland, snow surface roughness features that are more pronounced in winter than summer can notably increase the rate of chemical transport in snow, assuming similar wind conditions (Albert and Hawley, 2002).

Snow permeability strongly influences snow-atmosphere exchange, and depends mainly on snow layering and snow microstructure (Bartels-Rausch, 2012). Although snow density has been commonly applied in the past to estimate permeability, it only correlates poorly in terms of air transmissibility (Albert et al., 2000). Permeability in a seasonal snowpack can change by two orders of magnitude over the course of the winter (Domine et al., 2008). Snow permeability can also vary by almost one order of magnitude between different snow layers within one snowpack (Albert et al., 2000).

It is also important to note that artificial ventilation of snowpack can be induced by certain chemical measurement techniques. Measurement methods that rely on pumping of interstitial air from the snowpack for chemical analysis/detection often require flow rates on the order of liters per minute, which causes advection-dominated flow and mixing of concentrations of analyte from various depths in the snowpack (Albert et al., 2002). As such, measured intersti- tial air chemical concentrations may not represent the true, local concentration at a given point in a snowpack.

\subsection{The role of seasonal snowmelt in modifying organic contaminant behavior in watersheds}

Snow (and associated contaminants) can experience various processes once deposited to the surface. As discussed in Sect. 3.2, contaminants may re-volatilize to the atmosphere after deposition. However, contaminants that remain associated with the snowpack can be subsequently released upon snowmelt. In all but the most extreme environments, seasonal snowmelt occurs, and this can significantly impact the local and regional hydrology, nutrient cycles and contaminant fate. For much of the Arctic and at lower elevations in alpine regions, the snow melts completely by the end of summer (e.g. Armstrong, 2001), but warming is leading to a shortening of the snow season (Olsen et al., 2011 and references therein; Derksen and Brown, 2012).

The snowmelt process is influenced by many factors including air temperature, insolation, topography, snowpack depth, presence of ground frost/permafrost, and rainfall events. The resulting discharge can include both "new water" (which originates from snowmelt and spring rainfall) and "old water" (which originates from groundwater and soil water), and serves to transport not only dissolved species, but also particulate materials. In many regions with an extended seasonal snowpack, snowmelt is characterized by a relatively quick onset and fast melt period (called the spring "freshet") that can deliver concentrated pulses of contaminants to surrounding soils and waters with potentially serious impacts on ecosystem health.

There is field evidence of contaminant amplification during snowmelt. Lafrenière et al. (2006) noted that organic contaminant concentrations in early melt water from a remote alpine area were much higher than in the snowpack, and even the more hydrophobic compounds were highly concentrated in melt water. Bergknut et al. (2011) noted that as much as $71 \%$ of the annual export of PCBs and $79 \%$ of that of the PCDD/Fs from a Boreal catchment in Northern Sweden occurred during the snowmelt induced spring flood, a percentage exceeding considerably the contribution that the spring freshet makes to the annual flow of water $(52 \%$ to $66 \%$ ). The higher percentage for the contaminant export was attributed to significant amounts of melt water reaching streams through overland flow. Comparing snowmelt runoff in an urban area during two subsequent years, Meyer et al. (2011a) observed higher peak concentrations of the pesticides chlorothalonil and $\gamma-\mathrm{HCH}$ in stream water in the year when the snowpack was thicker and when a higher proportion of run-off occurred by overland flow rather than subsurface flow. PAH transport in this urban watershed during snowmelt was found to correlate strongly with run-off rates, which in turn were controlled by the intensity of melting (Meyer et al., 2011a). Concentrations of PAHs during high 
Table 2. Types of snowpack elution behavior observed in the laboratory. Release profiles based on experimental data; example contaminants that follow these elution profiles are also listed.

\begin{tabular}{llll}
\hline Type & Timing of release & Release profile & Contaminant characteristics \\
\hline 1 & early during melt & water soluble & $\begin{array}{l}\text { atrazine, chlorothalonil, short } \\
\text { chain PFCAs }\end{array}$ \\
\hline
\end{tabular}

2 at the end of melt

early during melt and at
the end of melting

flow conditions were as much as two orders of magnitude higher than during low flow. Because of the 10 times higher run-off, PAH transport in the river during the spring freshet was three orders of magnitude higher than during normal flow (Meyer et al., 2011a). Also the flow of long chain perfluorocarboxylic acids (PFCAs), believed to be largely particlebound, had peak concentrations during the period of maximum snowmelt run-off, likely due to the mobilization of contaminated particles under high flow conditions (Meyer et al., 2011b).

Incidentally, dilution of compounds by the high run-off occurring during snowmelt is also possible, mostly for compounds that do not have primarily atmospheric origin. Nonatmospheric watershed sources may become diluted by melt water containing low concentrations of such contaminants, at least as long as these are not particle bound and the remobilization of solids counteracts this dilution effect. An example of this phenomenon is the concentrations of short chain
PFCAs in an urban creek, which dipped during the spring freshet (Meyer et al., 2011b), in contrast to the behavior of long chain PFCAs mentioned above.

Snow can contribute to contaminant amplification not only at the watershed scale, but also on the scale of the snowpack itself (Meyer and Wania, 2008). It had been established for quite some time that early melt water fractions are enriched in inorganic ions (Johannessen and Henriksen, 1978; Tsiouris et al., 1985). Mechanistically, this is explained by a melt water front percolating down a snowpack and dissolving the ions that have been excluded from the ice matrix and are present within a liquid-like layer at the snow grain surface (see also Bartels-Rausch, 2012). When late melt water forms and percolates through the snowpack, most of the ions have already been eluted. Table 2 describes various types of snowpack elution behavior observed experimentally, and the types of contaminants most likely to exhibit a particular release profile. Similar to the early release of ions in melting 
snow, Type 1 (Table 2) release was observed for water soluble organic contaminants during studies involving artificially generated and contaminated homogeneous snow that was subjected to controlled melt conditions (Schöndorf and Herrmann, 1987; Meyer et al., 2006, 2009a). In fact, elution curves of water soluble organics, which are estimated to partition predominantly ( $>90 \%$ ) to the liquid water phase present in a melting snowpack, closely resembled electrical conductivity measurements in the melt water (Meyer et al., 2009a, b). Because of the larger molecular size of organic contaminants, exclusion from the ice matrix can be assumed to be even more complete than that of inorganic ions (Kammerer and Lee, 1969). In laboratory experiments, the first quarter of the melt water contained as much as three quarters of the total load of water soluble chemicals, such as the pesticide atrazine. The first melt water fraction had concentrations in excess of five times the average snow concentration (Meyer et al., 2009a). Preferential enrichment of water soluble organic contaminants was also observed in the field, as Lafrenière et al. (2006) noted the strongest enrichment in early melt water samples for HCHs.

The opposite behavior was observed for particle-bound organic substances in controlled melting experiments, and is shown as Type 2 release in Table 2. Because snow, in particular if it has undergone repeated freeze-thaw cycles, often acts as a particle filter, particle-sorbed substances are retained in the melting snowpack to be released only at the very end of the melt. Examples of contaminants behaving this way are the larger PAHs (Meyer et al., 2009a), the longer chain semifluorinated alkanes used in skiwaxes (Plassmann et al., 2010), and mercury (Mann et al., 2011).

Particle sorption is not the only reason for contaminant enrichment in late melt water fractions. A late release (Type 3, Table 2) is also observed for somewhat water soluble substances that sorb strongly to the snow grain surface, but instead of being released only at the very end of the melt period, concentrations in the melt water tend to gradually increase in a late stage of melting when the snow surface area and thus the snow's sorptive capacity is diminishing and disappearing. Such behavior has been observed for long chain PFCAs (Plassmann et al., 2011) and is predicted for pesticides such as chlorpyrifos (Meyer and Wania, 2011a).

Some substances' sorption behavior is such that they are only partially particle-sorbed in snow. Their release from melting snow is then characterized by an early elution of the fraction dissolved in water and a second late peak associated with the release of particles from the snowpack (Type 4, Table 2). Which one of these peaks dominates not only depends on the contaminant's partitioning properties, but is also strongly dependent on snowpack properties, such as the particle content (Meyer et al., 2009a, b; Meyer and Wania, 2011a). For example, in snow with very low particle content, even quite hydrophobic contaminants can be enriched in early melt water fractions (Lafrenière et al., 2006).
A peculiar release behavior with maximum melt water concentration in the middle of the melt period (Type 5, Table 2) was observed for intermediate chain length PFCAs (Plassmann et al., 2011). This release profile could only be explained by assuming that the strength of sorption of the compounds to the snow grain surface is declining during the snowmelt period, for reasons that are currently still unclear, but may be related to the changing ionic composition of the melt water (Plassmann et al., 2011). Also the release of mercury from a melting snowpack was found to be influenced by the ionic strength of the water used to make the artificial snow (Mann et al., 2011).

All five types of elution behavior observed experimentally (Table 2) could be reproduced with a snowpack melt model that simulates the sequential melting of several horizontal snow layers and the resulting downward percolation of melt water (Meyer and Wania, 2011a; Plassmann et al., 2011). The model assumes equilibrium partitioning between the various snowpack phases (snow grain surface, particulate matter, melt water, air-filled pore space), suggesting that thermodynamic considerations are sufficient to explain the differences in the elution behavior of different chemicals (Meyer and Wania, 2011a).

Both laboratory experiments and model calculations have been used to explore what snowpack and melt characteristics have the largest influence on the contaminant enrichment in melt water (Meyer et al., 2009b, Meyer and Wania, 2011a). The early elution of water soluble compounds (Type 1, Table 2) was found to be most pronounced in deep and aged snowpack that is melting rapidly, while it is attenuated in layered snow with hydraulic barriers and in snowpacks that are subject to bottom melt (Meyer et al., 2009b, Meyer and Wania, 2011a) (see Fig. 2 for an illustration of two different melt scenarios). The filtering of particles by the snow, and therefore release via Type 2 elution (Table 2) was enhanced in dense snow consisting of fine and facetted snow grains as well as by the formation of dirt cones (Meyer et al., 2009b).

The contaminant enrichment in melt water observed at the base of the snowpack may be reflected to different extents in the timing of concentration peaks in the receiving water bodies. In the case of the water soluble contaminants that peak early during snowmelt the concentration observed in receiving waters depends on the extent of ground infiltration and surface run-off, as was illustrated by the case of the pesticide chlorothalonil in an urban stream discussed earlier (Meyer et al., 2011a). The enrichment of particle-bound substances in the late melt water fractions is likely of little relevance for the timing of concentration peaks of such substances in the receiving rivers, because it is overwhelmed by the high particle loads caused by high run-off rates during snowmelt. In other words, highest water concentrations for such substances would likely occur during the period of highest runoff. In cases where melt water directly enters water bodies, such as occurs during glacial melt or when snow on ice covered lakes and oceans is melting, the timing of release from 
the snowpack base may be more relevant in understanding the timing of concentration peaks in the water.

Snow cover is not an efficient storage reservoir for all organic species. As discussed in section 3.2, more volatile substances are readily lost by evaporation back to the atmosphere. Some contaminants may also be degraded within the snow, as discussed in Sect. 3.9. Despite high thermodynamic forcing, contaminants may not be able to escape the snowpack in locations where freezing rain has sealed the surface, an occurrence which appears more frequently in a warming climate (e.g., Post et al., 2009), and in these special cases a higher proportion of the contaminant may enter the water cycle during the freshet. Generally, only the photochemically stable and less volatile organic contaminants will still be present to a large extent in a seasonal snow cover at the onset of melt. Empirically, it has not yet been established whether the annually averaged watershed retention of these organic contaminants is enhanced or diminished through the presence of a seasonal snow cover. However, we may surmise that contaminant retention in a watershed experiencing highly episodic run-off with very high, albeit short runoff rate maxima is lower than in a watershed where run-off occurs more uniformly. There are two reasons for this: (i) Whereas run-off conditions that favor infiltration to soils are expected to increase contaminant retention within the watershed, in particular for compounds sorbing to soil organic matter, overland flow is less likely to be "filtered" by passage through the ground. Snowmelt generates high run-off during times when the ground is often still frozen and thus largely impermeable, resulting in a higher portion of run-off occurring on the surface than below the ground. (ii) Very high runoff rates as may occur during snowmelt result in greatly enhanced potential for solid phase transport and thus in the mobility of particle-sorbed substances. Overall, we may therefore expect that not only are the maximum water concentrations higher in the presence of a seasonal snowpack, but so are the annually averaged water concentrations. Exceptions may be urban watersheds that experience intense rain events that resemble those during the spring freshet (Zhao and Gray, 1999).

The likelihood of detrimental effects of contaminants on aquatic species depends on the contaminants' toxicity, its concentration, and the period of exposure. Not only is the long-term average concentration in water relevant in this context, but also the short-term concentration variability, especially as it relates to seasonal biological cycles. Specifically, fluctuating concentrations can be more toxic than average concentrations (Ashauer et al., 2011). The specific timing of concentration peaks is crucial, namely whether they coincide with time periods of particular organism susceptibility or food uptake. Water concentrations strongly depend on a contaminant's input to a watershed, i.e. either the use and emission of the contaminant within the watershed or the rate of atmospheric deposition to watershed surfaces. However, water concentrations will also depend on the retention ca- pacity of the watershed, namely the fraction of the contaminant input that finds its way into the water compartment (Bergknut et al., 2011). In addition to contaminant properties such as partitioning behavior and degradability, many watershed properties will influence this retention capacity, including relief, soil properties, and meteorological and hydrological characteristics. Watershed retention will almost certainly be subject to high temporal variability on a number of time scales, and thus will impact the extent and timing of concentration peaks and thereby also toxicity. The melt of a seasonal snow cover causes highest contaminant loads to occur in early spring, when organisms are at a particularly vulnerable stage of development. One particular motivation for seeking to understand the role of a seasonal snow cover in contaminant amplification is to achieve the ability to anticipate how climate change may impact aquatic organism exposure to contaminants (Macdonald et al., 2003a). Whereas rising temperatures may only slightly modify contaminant behavior in a watershed, small temperature changes can precipitate large changes in the characteristics of a seasonal snow cover (e.g. duration, depth, surface ice cover) and its melt (e.g. rate of melting). In other words, changes in contaminant pathways consequent to the melting of seasonal snow cover create a greater vulnerability to change than is the case in warmer regions.

\subsection{Fate of contaminants in melting glaciers}

Similar to Arctic environments, the scavenging and deposition of atmospherically transported POPs by snow plays an important role delivering POPs to alpine environments (Finizio et al., 2006; Vighi, 2006; Thies et al., 2007; Kang et al., 2009; Wang et al., 2010; Bogdal et al., 2010). High altitude environments, which are believed to be particularly susceptible to rapid climate change, provide cryospheric reservoirs of POPs (Blais et al., 2001b; Batterbee et al. 2009; Schmid et al., 2011). Blais et al. (2001a) have shown that a glacier-fed tributary was the dominant source of most POPs to a subalpine lake in the Canadian Rocky Mountains. They have also found that at least $10 \%$ of the glacier-melt discharging into this lake originated from the ice that was deposited during 1950-1970, a period with greater contamination by organochlorines (Blais et al., 2001b). The authors warned that enhanced glacial melt due to climate change may increase the release of contaminants to freshwater. Melting mountain glaciers have become a local secondary source for POPs (Blais et al., 1998; AMAP, 2005; Bogdal et al., 2009); measurements of a large range of POPs, including PCBs, $\mathrm{PCDD} / \mathrm{Fs}$ and organochlorine pesticides, revealed a remarkable re-increase of sediment concentrations in pro-glacial lakes directly fed by melt water from rapidly melting adjacent glaciers (Fig. 3). A comparison between sediment trends in vicinal Swiss Alpine lakes confirmed that sediment concentrations are increasing in glacier-fed lakes closely following the movement of the glacier front (Fig. 3a and b), while 


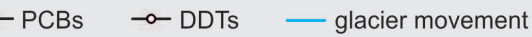

(a) pro-glacial Lake Oberaar

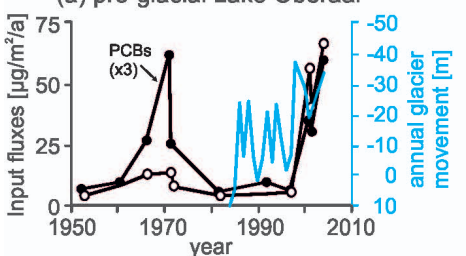

(b) pro-glacial Lake Stein

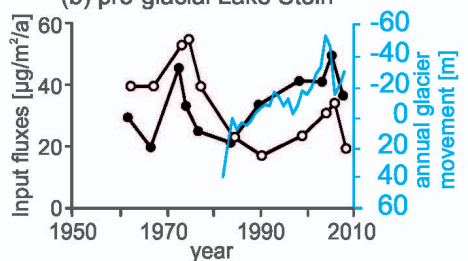

(c) non-glacial Lake Engstlen

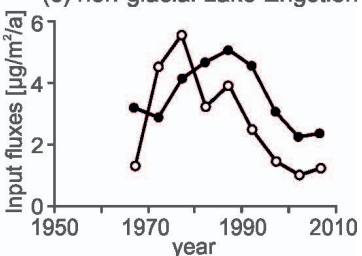

Fig. 3. Annual input fluxes of PCBs and DDTs (left y-axes) into sediment in three Swiss Alpine lakes including (a) the pro-glacial Lake Oberaar, (b) the pro-glacial Lake Stein, and (c) the non-glacial Lake Engstlen. For pro-glacial lakes (lakes immediately in front of or just beyond the limits of a glacier that are formed by or derived from glacier ice), the annual movement of the adjacent glacier is provided (right y-axes) with a positive value corresponding to a glacier growth and a negative value to a glacier retreat. Note that the values for PCBs in Lake Oberaar have been multiplied by three to fit to the y-axis scale. Figure adapted from Bogdal et al. (2009) and Schmid et al. (2011).

in non-glacial lakes concentrations are following a decreasing trend expected by emission reduction measures taken a few decades ago (Fig. 3c) (Schmid et al., 2011).

Coupling of a dynamic chemical fate model for PCBs, DDTs, and PCDD/Fs based on historical use and emission scenarios for these POPs with a transient glacial ice flow model enabled further confirmation of this glacier hypothesis and provided insight into the interconnection between contaminant-, glacier-, and climate-dynamics (Bogdal et al., 2010). It could be shown that since the 1990s, climate change has resulted in an acceleration of the release of POPs stored in Alpine glaciers. A steady-state climate would also have resulted in a release of contaminants but at a much slower rate. Due to climate warming, POPs are released earlier and more concentrated by glacial melt water. The release of chemicals may be further boosted if glacier melting continues to accelerate in the future. Between 1999 and 2008, the Swiss glaciers lost about $12 \%$ of their ice volume, whereas the extraordinarily warm summer of 2003 caused a volume loss of $3.5 \%$ (Farinotti et al., 2009).

Locally the release of POPs during the glacial melting season may represent a relevant source of toxic compounds to sensitive mountain ecosystems and may affect biota. Melting glaciers have also been hypothesized as a source for the continuing exposure to DDT of Adélie penguins from the Western Antarctic Peninsula (Geisz et al., 2008).

\subsection{Contaminant occurrence and processing in the sea-ice snowpack and sea-ice}

Relatively few studies have examined the occurrence of organic contaminants in the sea-ice system, largely due to logistical difficulties such as gaining access at the right time of the year. However, given the extensive areas covered by sea-ice and the dynamic nature by which organic contaminants can associate with and accumulate in snow and ice and be transported and/or released during periods of melt (see Sect. 3.3) sea ice studies are warranted. The transport of seaice across the Arctic Ocean is an important process within the global cryosphere, as part of the freshwater cycle, and possibly for the movement of contaminants contained within or deposited upon the ice (Pfirman et al., 1995; Lange and Pfirman, 1998). Simulations of contaminant transport by ice (Pavlov, 2007) have specifically investigated the potential for contaminants located in the vicinity of river-mouths of major rivers flowing into the Arctic Ocean, the Bering Strait, the White Sea on the northwest coast of Russia, and in the FaroeShetland Channel to be transported elsewhere over a period of $15 \mathrm{yr}$. The model results support the concept that contaminated sediments from the East Siberian rivers (Melnikov et al., 2003) may be transported with the ice into the Central Arctic Ocean over a period of several years, eventually reaching the marginal ice zones (MIZ) of the Western Arctic and the Barents Sea (Gustafsson et al., 2005) where they are released when the ice melts. Changes in the locations of ice formation and melting, and in the types and amounts of ice induced by climate change, therefore, may have the capacity to alter the export of contaminants from the Arctic. Although we have reasonable estimates of the volumetric transport of sea ice, the transport of particles contained within sea ice, and some contaminant loads carried by that ice (Macdonald et al., 2005), the magnitude of this transport pathway for most POPs remains poorly quantified. The dramatic change in ice climate (Stroeve et al., 2007, 2012) which has already witnessed the replacement of almost half of the multi-year ice with seasonal ice, means that much of the sea ice no longer functions as multi-year accumulator and transporter. Instead, whatever contaminant load the ice accumulates, either from atmospheric deposition or sediment resuspension is returned to the ocean surface within the same year.

\subsubsection{The effect of sea-ice formation processes and brine rejection on contaminants}

Figure 4 illustrates the processes associated with sea-ice formation and growth in the Arctic over a winter season. The behavior of organic contaminants associated with these processes, including the growth of sea-ice during fall/winter and 
FALL

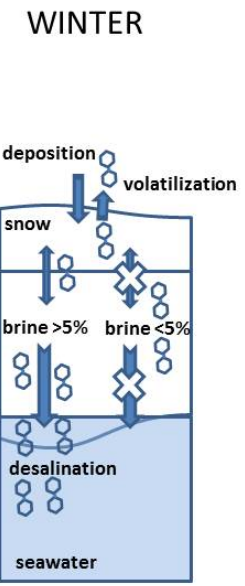

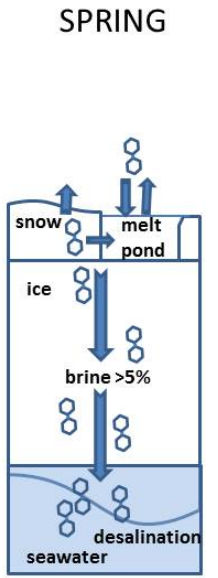

Fig. 4. Sea-ice formation and growth during the winter season and associated behavior of POPs. During sea-ice growth in the fall and winter, chemical contaminants in the seawater become entrapped with brine in the forming ice. Subsequent freezing-out concentrates the brine resulting in the enrichment of contaminants. If the brine fraction of the ice exceeds $5 \%$ then desalination may occur with subsequent ejection of the contaminants into the beneath-ice environment. Upward percolation of brine may also occur into the overlying snowpack. During winter most of the ice-column exhibits a brine content $<5 \%$ resulting in reduced brine movement and the "locking" of contaminants in the ice. During spring, the brine fraction increases again due to melt and further desalination may occur into the under-ice seawater. Contaminants deposited in the snowpack are subject to exchange processes with the atmosphere. Remaining residues present in the snowpack during spring melt may percolate into the sea-ice or be flushed into meltwater ponds. These dynamic processes concentrate and flush contaminants from seasonal, first-year ice, which is the dominant sea-ice in a warming Arctic.

the desalination of seasonal sea-ice is also illustrated and is based largely on observations conducted as part of the Canadian Circumpolar Flaw Lead (CFL) system study. This study was conducted in the eastern Beaufort Sea and Amundsen Gulf in the Canadian Arctic, including a detailed examination of the behavior of $\alpha$-and $\gamma-\mathrm{HCH}$ in sea-ice (Pućko et al., 2010a, b, 2011a). The sea-ice snowpack is typically shallow $(<1 \mathrm{~m})$ and usually is comprised of a windblown hardpack, interspersed with, or overlying, layers of large, weathered snow crystals (e.g. depth hoar) with a surface dominated by ice pressure ridges and wind-shaped sastrugi. With the onset of spring, snowmelt can give rise to meltwater ponds which cover substantial areas of the sea ice. Short term observations of POPs in the sea-ice snowpack revealed a significant loss of $\alpha$-and $\gamma$-HCH (by $\sim 40 \%$ ) via re-volatilization when windy conditions were encountered on the sea ice. This was attributed to the reduction of snow SSA, which in turn leads to increased snow density and reduced capacity for the snow to hold sorbed chemicals, occurring over relatively short time periods $(<24 \mathrm{~h})$ following fresh snowfall events (Pućko et

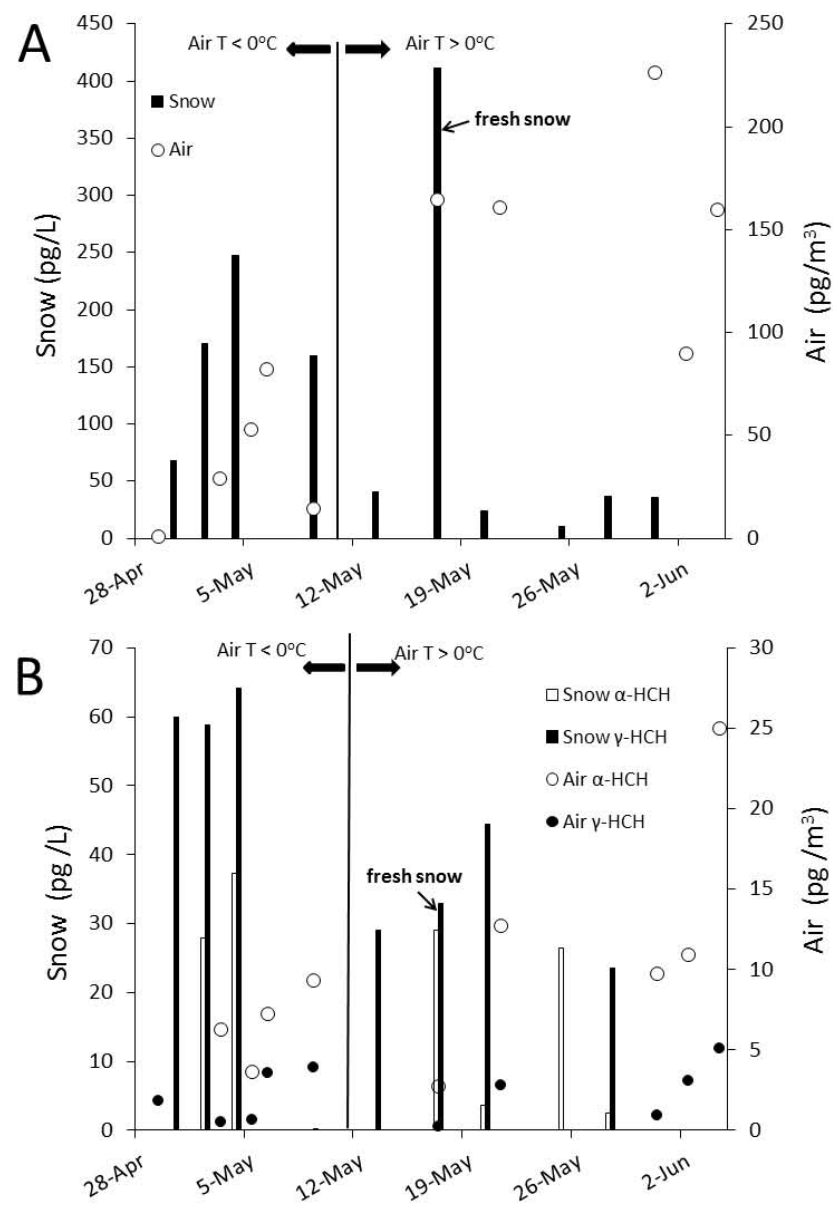

Fig. 5. Time-series of HCB (top) and $\alpha$ and $\gamma$-HCH (bottom) concentrations in snow and air measured in the Amundsen Gulf, Canadian Arctic (April-June 2008). The vertical lines approximately denote the period when average air temperatures were at or above $0^{\circ} \mathrm{C}$. $\mathrm{HCB}$ and $\mathrm{HCH}$ concentrations in air are shown on the secondary y-axes. The average daily air temperature fluctuated around $0{ }^{\circ} \mathrm{C}$ from mid-May onwards with a corresponding reduction in the snowpack depth and cover and occurrence of melt-ponds on the seaice surface by late May. When air temperatures are $>0{ }^{\circ} \mathrm{C}$, concentrations of $\mathrm{HCB}$ and HCHs are generally lower in the snow (excluding fresh snowfall) and the air concentrations are on average higher than when air temperature was $<0^{\circ} \mathrm{C}$, indicating exchange between the snowpack and the atmosphere. Data from Codling et al. (2012).

al., 2011a). While SSA would be the best parameter to use in this type of study, only density measurements were available during this particular field campaign, and as such served as a proxy for SSA. Regular measurements of the sea ice snowpack conducted over the late winter and into spring (March to June) revealed significant inverse relationships between chemical concentrations in snow and snow density for hexachlorobenzene (HCB) and the lower chlorinated PCB congeners (Codling et al., 2012). A weaker relationship was apparent for $\alpha$-and $\gamma$-HCH and cis- and trans-chlordane, and no relationship was observed for PBDEs (congeners 47, 99 
and 100) and $\mathrm{C}_{4}-\mathrm{C}_{10}$ PFCAs. In this case, snow density was used as a surrogate for SSA, where samples of snow with higher density are assumed to have lower SSA (see Legagneux et al., 2002) based on the observations of the different snow types encountered during the CFL campaign. Interestingly, for the longer chain PFCAs $\left(\mathrm{C}_{11}-\mathrm{C}_{14}\right)$ a significant positive relationship was apparent with snow density $\left(r^{2}=0.3-0.7, n=5\right.$ to $\left.10, p<0.05\right)$ indicating their accumulation or enrichment within higher density snow (with presumably lower SSA). However, the particle-bound fraction of these chemicals is likely to be significant (although this fraction was not analyzed separately) and the older, higher density snow may also effectively retain particulate matter, particularly following partial melt and water loss, which may account for the increase in concentrations. These relationships with density and hence SSA indicate the degree to which a chemical is vapor-sorbed to the snow crystals. Reductions in SSA are likely to result in evaporative loss of the more volatile chemicals, whereas lower volatility chemicals (e.g. PBDEs and PFCAs - the latter present in the snow in their anionic form) will be retained within the snowpack, especially if the compound has a significant particle-bound fraction. Figure 5 presents a time-series of contaminant concentrations (HCB, $\alpha$-and $\gamma-\mathrm{HCH}$ ) measured in the sea-ice snowpack of the Amundsen Gulf from late April to early June. The average daily air temperature fluctuated around $0^{\circ} \mathrm{C}$ from mid-May onwards, resulting in a notable reduction in the snowpack depth and cover, with the occurrence of melt-ponds on the sea-ice surface by late May. By early June, ice-cover in the Amundsen Gulf had decreased to $<40 \%$, compared to $\sim 98 \%$ prior to May. When air temperatures are $>0{ }^{\circ} \mathrm{C}$, concentrations of $\mathrm{HCB}$ and $\mathrm{HCHs}$ are generally lower in the snow (excluding fresh snowfall) and the air concentrations are on average higher than when air temperature was $<0^{\circ} \mathrm{C}$, indicating the dynamic nature of chemical exchange between the snowpack and the atmosphere.

What we know of the behavior of organic contaminants in the sea-ice (see Fig. 4) is based largely on the work of Pućko et al. (2010a, b) who examined $\alpha$-and $\gamma-\mathrm{HCH}$ in seasonal and first year ice during the CFL campaign. As seawater freezes, salts can be excluded from the bulk ice in a process known as "brine rejection", forming a highly variable sea ice matrix consisting of ice crystals and inclusions of brine and air (Bartels-Rausch, 2012). However, little was known previously about the behavior of contaminants during this freezing process. Pućko et al. (2010a, b) showed that $\mathrm{HCH}$ was generally associated with the brine fraction of sea ice, but as much as $40 \%$ could remain within the ice crystal matrix until the final stages of melt. $\mathrm{HCH}$ concentrations were found to be higher in younger ice that contained brine (brine salinity $\gg 50 \mathrm{ppt}$ ). The concentrations of both $\mathrm{HCH}$ isomers and their vertical distributions in the ice were highly dependent on the initial entrapment of brine in young ice and the subsequent desalination process.
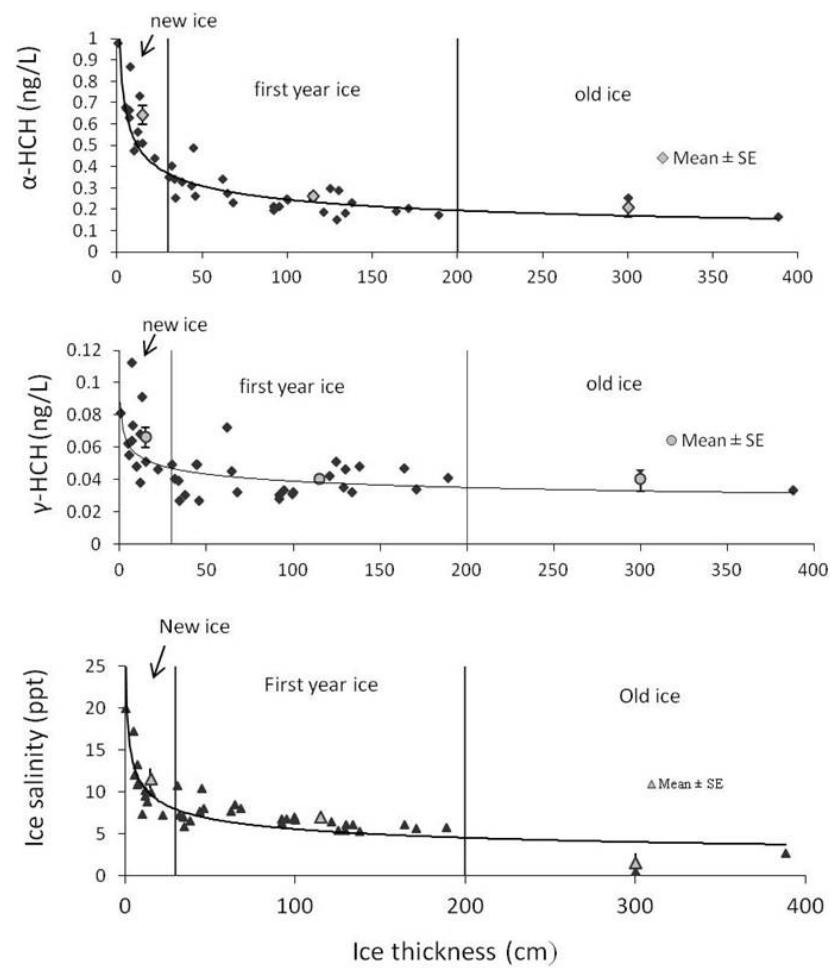

Fig. 6. Dependence of $\alpha-\mathrm{HCH}$ (top) and $\gamma-\mathrm{HCH}$ (middle) concentrations and ice salinity (bottom) on sea ice thickness (adapted from Pućko et al., 2010a). Both HCH isomers decreased exponentially with increasing sea ice thickness following the sea ice desalination curve. The correlations observed between $\mathrm{HCH}$ concentrations, salinity and ice thickness imply that brine rejection is also accompanied by $\mathrm{HCH}$ rejection.

Concentrations of both $\mathrm{HCH}$ isomers decreased exponentially with increasing sea ice thickness following the sea ice desalination curve (Fig. 6). The correlations observed between $\mathrm{HCH}$ concentrations, salinity and ice thickness imply that brine rejection is also accompanied by $\mathrm{HCH}$ rejection which, in turn, will yield elevated concentrations of these chemicals in the brine-channels within the ice and in the beneath-ice seawater during periods when brine exits in the sea ice. HCH levels in the brine in the winter were approximately 13 times higher than in bulk ice due to the freezing out effect as new ice forms, reaching $4.0 \pm 0.3 \mathrm{ng} \mathrm{L}^{-1}$ for $\alpha$ $\mathrm{HCH}$, and $0.42 \pm 0.01 \mathrm{ng} \mathrm{L}^{-1}$ for $\gamma-\mathrm{HCH}$. These concentrations represent some of the highest $\mathrm{HCH}$ concentrations measured in the Arctic marine environment, exceeding under-ice water concentrations by a factor of $\sim 3$ in the spring (AprilMay) (Pućko et al., 2010a, b). In spring, (i.e. from mid-April to mid-May) $\mathrm{HCH}$ concentrations in ice brine were found to decrease gradually with time as the brine volume fraction increased (due to melting of the ice crystal matrix) and the brine salinity decreased (Pućko et al., 2010b). Therefore $\mathrm{HCH}$ concentrations in newly-forming sea ice depend primarily on the initial sea water concentration, the rate of 
Air concentration, $\mathrm{pg} / \mathrm{m}^{3}$
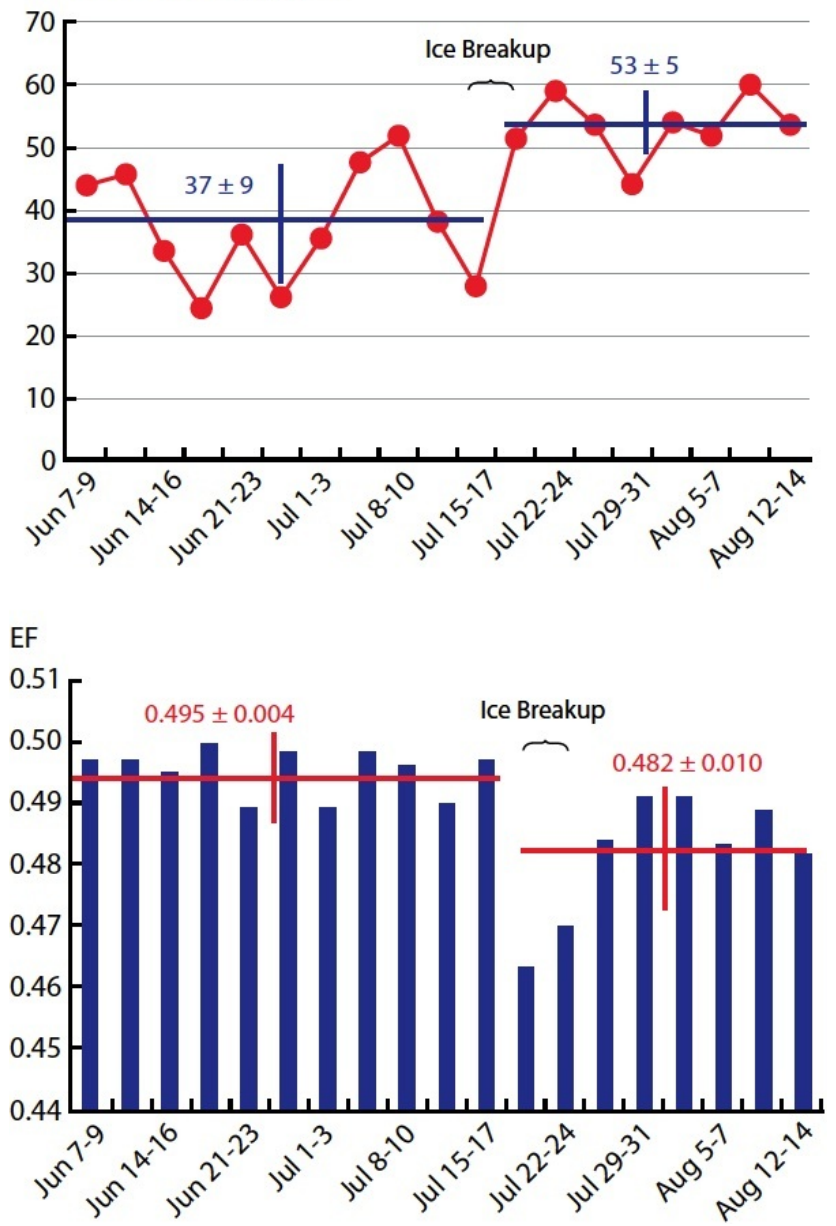

Fig. 7. Average air concentrations (top) and enantiomer fractions (bottom) at Resolute Bay before and after the seasonal ice melt, Jantunen et al. (2008). During winter/spring ice coverage, $\alpha-\mathrm{HCH}$ in the air had a racemic composition (i.e. $\mathrm{EF}=0.5$ ) but with the loss of ice cover in spring, the concentrations in the air rose considerably from the winter values, and the EF changed towards the signature of the surrounding waters Reported errors represent 1 standard deviation based on method uncertainties. Picture modified according to $\operatorname{AMAP}(2011 b)$.

ice formation ( $\mathrm{HCH}$ accumulation) and desalination (concurrent $\mathrm{HCH}$ rejection) until the combination of declining atmospheric temperature and increasing insulation by a thickening ice cover permit the ice to cool sufficiently for its brine volume fraction to drop below $5 \%$ (the fraction below which there is little brine movement within the ice). In the winter, most of the ice column exhibits a brine volume fraction below $5 \%$; throughout this time the accumulating $\mathrm{HCH}$ concentrations at the bottom of the ice will become locked as the ice grows, thereby initially reflecting the $\mathrm{HCH}$ concentration of the water beneath the ice. Following the first snowfalls on newly formed ice, upward migration of brine from the surface of the ice will affect levels of salt and $\mathrm{HCHs}$ in the snow by diffusion out of the shallow "slush" layer, which maintains a brine volume fraction $>5 \%$ (see Pućko et al., 2011a). The extent to which snow can affect $\mathrm{HCH}$ levels in sea ice (and presumably other contaminants that possess similar physicochemical properties) is significantly smaller, and may be restricted to a short period in spring when the ice warms enough for its brine volume fraction to exceed $5 \%$. Further research is needed to determine whether this behavior applies to other contaminants, particularly some of the emerging POPs like the PFCAs, which are present in seawater and hence will be entrained in newly forming sea-ice and also deposited to the surface of the ice with successive snowfall events.

A notable summer field investigation in the MIZ of the Barents Sea examined PCBs in ice (multi-year ice), snow and beneath-ice seawater as well as the micro-environments of ice-interstitial water and ice-rafted particulate matter (Gustafsson et al., 2005; Sobek et al., 2006). PCB concentrations, however, were found to be relatively low (e.g. PCB52 in snow and seawater was observed in the range of 0.1 $0.3 \mathrm{pg} \mathrm{L}^{-1}$ ), with little evidence of contaminant enrichment in the various sea-ice sub-compartments, like the ice-melt water ponds. However, this field campaign was conducted during the warmer months of July and August when substantial freeze-thaw activity and melting had occurred, and when considerable time had elapsed to allow atmosphere-surface water gas exchange.

In the last decade the proportion of older, multiyear ice ( $>2 \mathrm{yr}$ old) in the Arctic Ocean has diminished markedly (e.g. $>4 \%$ decrease from 2005 to 2008) with a corresponding increase in younger ice ( $<1 \mathrm{yr}$ old) (Kwok et al., 2009; Stroeve et al., 2012). Diminishing perennial sea ice in favor of annual ice will affect the dynamics of organic contaminants in the sea-ice system, with a widespread predominance of the ice-brine enrichment pathway affecting the exposure of ice-associated organisms such as ice algae in the spring. The entrainment of waterborne contaminants within seasonal seaice and their subsequent possible enrichment in ice-brine provides a mechanism resulting in the concentrated re-release of contaminants to marine waters. The presence of ice-brine in younger ice also allows greater interaction of contaminants between the snowpack and the ice, with potential for downward migration or percolation from the snowpack into the ice, once brine levels increase with the onset of spring; again, providing a direct contaminant pathway to ice-associated organisms, which sit at the base of the marine food web. An additional concern is that contaminants stored in the winter snowpack over ice will in turn yield relatively contaminated melt water which will collect in melt ponds and accumulate as a buoyant layer under melting ice resulting in exposure for ice-associated biota at a biologically-important time of the year. 


\subsubsection{The effect of sea-ice on contaminants in the atmosphere}

In a warming Arctic, summer sea-ice has experienced significant retreat in the past three decades with decreasing area coverage, reduced growth after summer, delayed fall freezeup with a lengthened melt season, decrease in ice thickness over the central Arctic Ocean and a shift from a multi-year ice cover to ice less than a year old (Stroeve et al., 2007, 2012; Steele et al., 2008; Lindsay et al., 2009; Perovich, 2011). More open water enhances solar heat input resulting in a warming upper ocean with greater ice melt (Perovich, 2011). Changes in ice coverage and temperature increase in the upper ocean have significant implications for the exchange of contaminants between air and ocean. Contaminants that have accumulated in the sea-ice may be released during melt, and those stored in sea water may volatilize to the atmosphere when the Arctic Ocean opens. On the other hand, open water may receive more input of contaminants via atmospheric deposition. The net amount and direction of contaminant flux between air and water depends on the fugacity gradient between air and water and the partitioning properties of the compound, which are temperature dependent. Studies have shown that sea-ice is an effective barrier for air-ocean exchange of contaminants (Jantunen and Bidleman, 1996). During an expedition in June-August 2004, Gioia et al. (2008) performed coupled air and water concentration measurements from which they inferred that deposition dominates over volatilization for PCBs in the Arctic region. However, near the MIZ $\left(78-79^{\circ} \mathrm{N}\right)$, their calculations show higher net deposition of PCBs because of higher PCB air concentrations. It is uncertain whether this was because melting ice margins were a source of PCBs to the atmosphere or whether more complex ice-water-atmosphere interactions were occurring (e.g. coupled to phytoplankton activity). Recent studies have predicted net deposition of HCB into the Arctic Ocean (Su et al., 2006; Lohmann et al., 2009; Wong et al., 2011) and exchange directions varied for $\alpha$-and $\gamma-\mathrm{HCH}$, 2,4-dibromoanisole (DBA) and 2,4,6-tribromoanisole (TBA) by season and locations (Wong et al., 2011).

Significant reductions in ice cover in late summer, as observed over the western Arctic Ocean in recent years, will lead to increased evaporation of semi-volatile contaminants formerly trapped below the sea ice. $\alpha-\mathrm{HCH}$ and other volatile POPs (e.g. HCB) are sensitive to this temperature effect (e.g. Li et al., 2004). Measurements made as early as 1993 (Jantunen and Bidleman, 1996) showed that atmospheric declines in $\alpha-\mathrm{HCH}$, due to curtailment of technical-HCH use by China and India (e.g. Li and Macdonald, 2005), resulted in a reversal of the air-sea flux direction of HCHs from net deposition in the 1980s to net volatilization in the 1990s. Insight into air-surface exchange over the Arctic Ocean has been gained by examining the enantiomers of chiral organochlorine pesticides (e.g. Jantunen et al., 2008). For example, $\alpha-\mathrm{HCH}$ exists as two enantiomeric forms; $(+) \alpha-\mathrm{HCH}$ and
$(-) \alpha-\mathrm{HCH}$, which can be separated on a chiral-phase chromatography column. Importantly, enantiomers have the same physical-chemical properties, so transport processes in the environment or abiotic reactions do not discriminate between the enantiomers (Bidleman and Falconer, 1999). In contrast, metabolic processes such as microbial activity may selectively deplete one enantiomer over the other. Enantiomer fractions $(\mathrm{EFs})($ i.e. $\mathrm{EF}=(+) /[(+)+(-)])$ are commonly used to depict enantioselective processes and hence are used to discriminate between environmental sources and compartments where enantioseletecive degradation may have occurred. An EF value of 0.5 represents a racemic mixture i.e. the $(+)$ and $(-)$ forms are in equal proportions. This is usually the case for fresh, technical formulations of a pesticide. Deviations of EF from 0.5 represent a "weathered" signal. Measurements of the enantiomeric composition of $\alpha-\mathrm{HCH}$ in air and surface seawater in Arctic Canada (Jantunen et al., 2008; Wong et al., 2011) show that more open water is allowing for volatilization from the ocean reservoir. Both Jantunen et al. (2008) and Wong et al. (2011) showed that during winter/spring ice coverage, $\alpha-\mathrm{HCH}$ in the air had a racemic composition (i.e. $\mathrm{EF}=0.5$ ) but with the loss of ice cover in spring, the concentrations in the air rose considerably from the winter values, and the EF changed towards the signature of the surrounding waters (Fig. 7). Changes in EF upon ice breakup allow non-racemic $\alpha-\mathrm{HCH}$ in sea water to volatilize and mix with nearly racemic atmospheric $\alpha-\mathrm{HCH}$ advected by long-range transport, providing strong evidence of seasonal "re-emission" of $\alpha$-HCH from an ice-free ocean surface.

Pućko et al. (2011b) evaluated the evolution of the $\alpha$ $\mathrm{HCH}$ inventory in the Beaufort Sea and found that between 1986 and 1993, the inventories increased due to loading via ocean currents, while gas exchange, river inflow and ice export were negligible $\alpha-\mathrm{HCH}$ input/output routes. Degradation processes could explain the decrease in observed $\alpha-\mathrm{HCH}$ concentrations between 1993 and 2007 and they anticipate that the majority of $\alpha-\mathrm{HCH}$ could be degraded in the Beaufort Sea by 2020.

Concentrations of many organic contaminants in the Arctic atmosphere during the past ten years have varied regionally but are generally trending downward (Hung et al., 2010). An exception to this is HCB, a former pesticide and still an unintended byproduct of various industrial chemical processes. Increases in HCB concentrations in the atmosphere have been observed since 2003 at the Zeppelin (Svalbard) mountain research station (Fig. 8). A similar increasing trend in HCB was also observed at the Canadian High Arctic station of Alert (Wang et al., 2010). Overall, the downward trends of organochlorine concentrations in air are due to the reduction of use/production of these compounds. However, it is currently unclear what has caused the change in the downward trend of HCB concentrations in air since 2003 near Zeppelin. Becker et al. (2012) discuss the recent upturn in HCB concentrations and consider several hypotheses 


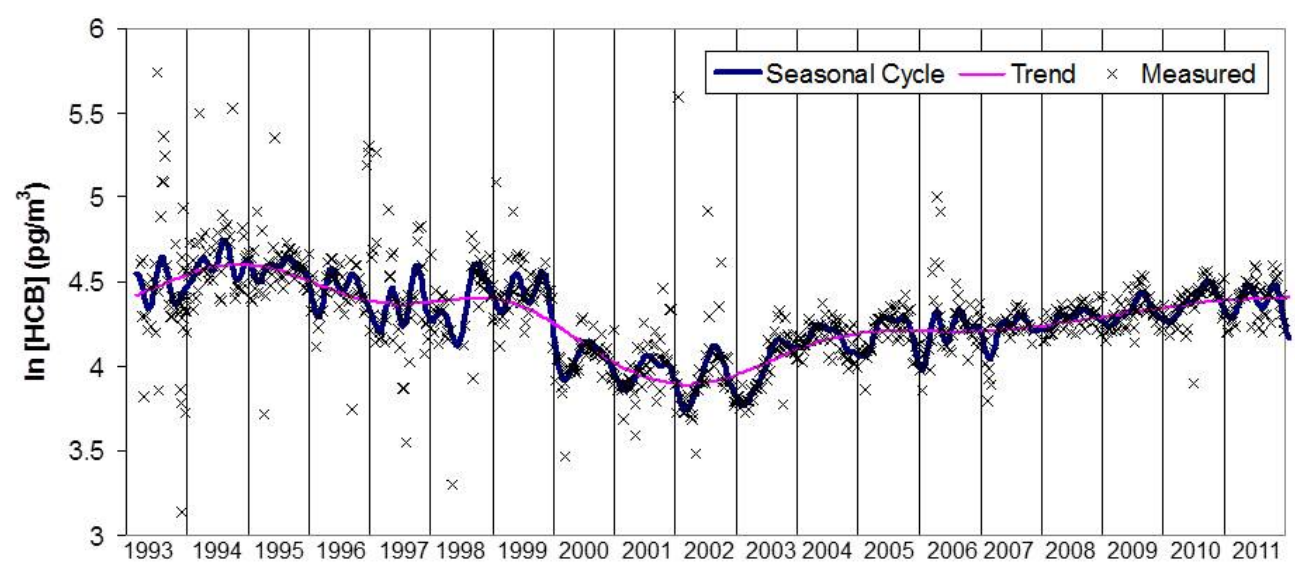

Fig. 8. Temporal trend for hexachlorobenzene (HCB) in air at Zeppelin, Norway during the monitoring period 1993-2012. Data obtained from http://www.nilu.no/projects/ccc/onlinedata/pops/index.html. The trend and seasonal cycles were developed using the Digital Filtration Technique described in detail in Nakazawa et al. (1997).

for this behavior. Revolatilization from previously contaminated soils and vegetation may influence atmospheric concentrations (Bailey, 2001; Barber et al., 2005), as well as the presence of HCB impurities in currently used pesticides. The fungicides, chlorothalonil and quintozene, and the arachnicide, tetradifon, have been shown to contain HCB as impurities (Gouin et al., 2008). Besides the possible use of HCBcontaminated pesticides, these increases may be related to a reduction in sea ice cover on the west coast of Spitsbergen, where Zeppelin is located, which has become ice free in the past 6-7 yr. The reduced ice cover in Fram Strait is a consequence of the significantly increased inflow of warm, surface North-Atlantic water (Slubowska-Wodengen, 2007; Nilsen et al., 2008). Although dramatic ice retreat has been observed in other parts of the Arctic, a permanently ice-free state at $80^{\circ} \mathrm{N}$ is unique. Ma et al. (2011) further analyzed the time series of POPs in Arctic air measured at Zeppelin and Alert to reveal evidence of remobilization of POPs trapped in Arctic environmental sinks (ice/snow, land and water) due to Arctic warming and sea ice retreat. They hypothesized that the overall downward trends observed in measured atmospheric POP concentrations caused by decreasing emissions, changing locations of sources and environmental degradation may have masked any climate change influence on atmospheric POPs. By statistically removing the declining time trends, the underlying residuals showed increasing tendencies when Arctic sea-ice retreat sped up (Stroeve et al., 2007). The statistical detrending and correlation analysis of Ma et al. (2011) were almost entirely performed using summertime datasets in order to minimize the effects of low-latitude emissions and seasonality in the data (since Arctic ice melt is most significant and POPs input from southerly sources is lowest in summer). They found that concentrations of most POPs were positively correlated with summer surface air temperatures and negatively correlated with sea-ice extent from 2000 to 2009, at significance levels of $90 \%$ or more.
As part of a critical review on the implication of global climate change for human exposure to organic contaminants in the Arctic, Armitage et al. (2011) examined the sensitivity of the accumulation of organic contaminants in the Arctic as a result of sea-ice cover reduction/elimination. An increase in primary productivity in aquatic systems, related to changes in sea-ice cover and nutrient availability, would affect the distribution of organic contaminants between the freely dissolved phase and the particle-bound fraction. While the former drives pelagic food web exposure and is available for volatilization to the atmosphere, the latter would enhance deposition to the sediments and deep ocean. Their calculations showed that the freely dissolved fraction would only increase for very hydrophobic contaminants with unrealistic temperature-dependencies and temperature increases in the water column. However, the magnitude of change is uncertain. Although salinity would affect organic chemical solubility and partitioning properties, the magnitude of changes in salinity linked to climate change (e.g. melting ice/snow) are unlikely to affect such properties to a great extent as compared to other changes. Their study concluded that human behavioral change could be potentially more influential to exposure than changes to the physical environment.

\subsection{Preservation of contaminant deposition records in ice cores}

In persistently cold climates, snow will continue to accumulate and at higher depths form firn as it is compressed by the snow above. During this time, interstitial air between snow grains can be exchanged with the atmosphere above the snowpack, until the pores eventually close off and air is trapped. As pressure increases, firn is eventually compressed into ice, and this ice (and the air trapped within) can serve as an invaluable record of past atmospheric composition. In geographic locations where snow is converted to firn, and 
eventual permanent ice, it is possible to examine contaminant records preserved in ice cores. Anthropogenic organic contaminants have been measured in ice cores collected in a variety of locations including Svalbard, Norway (Isaksson et al., 2003; Ruggirello et al., 2010; Hermanson et al., 2010); Colle Gnifetti in the Swiss/Italian Alps (Gabrieli et al., 2010); Mt. Everest (Wang et al., 2008); Lys Glacier, Italy (Villa et al., 2006) and Ellesmere Island, Canada (Gregor et al., 1995). Using literature-reported data, Wang et al. (2010) found correlations between climate variation patterns (including the El Nino-Southern Oscillation, the Siberia High pattern and the North Atlantic Oscillation) and deposition of DDT and $\mathrm{HCH}$ in ice cores from Mt. Everest (the Tibetan Plateau), Mt. Muztagata (in the eastern Pamirs) and the Rocky Mountains in North America. These associations suggest linkages between climate variations and organic contaminant distribution. It is difficult to segregate the relative extent of the influence of climate change from emission changes on the deposition of contaminants to ice and firn cores, but the records clearly show that deposition at given sites is a product of both the strength of emissions and other factors (winds, temperatures, secondary sources) that are strongly affected by climate variability and climate change. As emissions decrease, the secondary sources grow in relative importance and these are strongly controlled by climate.

Utilization of firn and ice cores in the Arctic is providing insight into the recent $(<$ decade) and longer-term (multi-decadal) accumulation history of POPs and other organic contaminants (e.g. currently used pesticides, brominated flame retardants, PFCAs) (Young et al. 2007; Hermanson et al, 2005, 2010; Ruggirello et al, 2010; Meyer et al., 2012). Contaminant accumulation in ice is unlikely to provide accurate depositional fluxes for a given year due to the post-depositional processes that can occur, such as revolatilization, degradation, deposition of POP-bearing particles to snow by wind pumping, or movement with percolating meltwater. For example, Jaffrezo et al. (1994) measured a 35-90 \% decrease in certain PAH compounds over the course of $4 \mathrm{yr}$ in a Greenland snowpit, likely due to chemical degradation. In order to reconstruct past atmospheric pollution and climate from Alpine ice cores, glaciers having negligible influence by percolating meltwater need to be selected because meltwater disturbs the annual layer structure. However, due to recent climate warming it becomes more and more difficult to find unaffected cold glaciers, particularly in temperate mountain regions. Eichler et al. (2001) drilled an ice core from the accumulation area of the glacier Grenzgletscher (Swiss Alps) at $4200 \mathrm{~m}$ a.s.l. and analyzed inorganic tracers. A significant deviation of the $\mathrm{Cl}^{-}$-to- $\mathrm{Na}^{+}$-ratio from the expected seawater ratio of 1.16 provided evidence for the transport of soluble chemical species with the percolating meltwater moving within this glacier. Today, the relevance of percolating meltwater for the conservation of organic contaminants within temperate ice is hardly known. Nonetheless, the few existing studies do provide an excellent assessment of relative contaminant accumulation history. Ice/firn cores taken in the Norwegian and Canadian Arctic provide information on geographical differences in sources and contaminant transport patterns. The valuable time-series provided by firn and ice cores could complement air monitoring efforts in the Arctic and elsewhere, particularly with respect to newer, emerging contaminants for which longer term measurements in air are lacking. Coordination of coring efforts and the tying together of different field programs (polar regions and alpine) may provide a useful endeavor for global monitoring efforts under UNEP. We note that accelerating climate change introduces a certain urgency in recovering these sorts of ice records given the ongoing wide-scale demise of small continental glaciers (e.g. Meier et al., 2007).

\subsection{Transport of contaminants by biota (biovectors)}

Biota that undergo seasonal migrations into the cryosphere, or that forage widely within the cryosphere and then converge at special locations, have the capacity to provide an efficient means to transport contaminants that bioaccumulate or biomagnify (Wania, 1998; Blais et al., 2007; Roosens et al., 2007; Corsolini et al., 2007). The cryosphere contains large and varied populations (100000 s-1000 $000 \mathrm{~s}$ of birds, fish and mammals) that are seasonal, or exhibit migratory behavior, or exhibit life cycles that include convergence into dense colonies or special locations. Animals have adapted these behaviors partly because winter precludes activities like foraging or nesting, and partly because seasonal ice cover controls access to locations favored for foraging. The example of recent dramatic change occurring in Arctic sea-ice cover (e.g., Stroeve et al., 2007, 2012), with 2012 now achieving the lowest ice cover on record, brings with it the inescapable conclusion that migratory behavior, foraging and regions of convergence will be at the vanguard of change. Indeed, ocean climate change may even lead to the establishment of new migratory behaviors and pathways (e.g., Nielsen et al., 2012).

In terms of regional or global contaminant mass balances, biovectors tend to be quantitatively small (Wania, 1998). For example, Zhang et al. (2001) estimated that sockeye salmon annually transported $\sim 1 \mathrm{~kg}$ of monomethyl mercury ( $\mathrm{MeHg}$ ) from the Pacific Ocean to rivers in Bristol Bay, Alaska. This mass would be approximately equivalent to $\mathrm{MeHg}$ held in the top $500 \mathrm{~m}$ of the North Pacific Ocean over an area of $\sim 50 \mathrm{~km}^{2}$ (based on MeHg measurements by Sunderland et al., 2007). Likewise Krümmel et al. (2003) estimated that 1 million adult sockeye salmon could transport $\sim 0.16 \mathrm{~kg}$ of PCB, which is comparable to the amount of PCB contained in the top $100 \mathrm{~m}$ of shelf water for an area of about $100 \mathrm{~km}^{2}$ or the amount of PCB transported by the flow into the Arctic Ocean through Bering Strait in about two days (based on PCB measurements for Arctic Ocean surface waters by Carrizo and Gustafsson, 2011). 
The above comparisons do, however, provide a strong caution in terms of the potential importance of biovectors in exposing special ecosystems to toxic chemicals. For example, in an extreme case where salmon converged on an Alaskan lake in numbers exceeding 20000 spawners per $\mathrm{km}^{2}$, Krümmel et al. (2003) showed that PCB depositional fluxes to sediments exceeded $3700 \mathrm{ng} \mathrm{m}^{-2} \mathrm{yr}^{-1}$, or about 8 times the loadings inferred for atmospheric deposition. Similarly, Evenset et al. (2007a) found that organochlorine contaminants delivered by birds to a remote arctic lake on Bear Island (Barents Sea) were equivalent to 30 times the atmospheric delivery mechanism. In other locations, authors point to soil concentrations for PCBs and pesticides that are 10 to 100 times those at sites not influenced by migratory animals (e.g., Roosens et al., 2007; Cabrerizo et al., 2012). Perhaps more importantly, the contaminant loadings associated with biovectors lead to pervasive biological exposure within the affected freshwater ecosystems (Gregory-Eaves, 2007; Evenset et al., 2007a). The leading species engaging in migratory behavior in the cryosphere include fish, marine mammals, and birds with the latter providing the bestknown examples for the Arctic (Evenset et al., 2004, 2007a, b; Michelutti et al., 2008, 2009; Foster et al., 2011) and Antarctic (Corsolini et al., 2007; Roosens et al., 2007; Nie et al., 2012). Although these migrations have the potential in some cases to deliver contaminants from temperate and tropical regions into polar regions, the more significant process involves redistribution within polar regions. Specifically, birds feed from surrounding productive ocean areas (e.g., polynyas or open waters), and rear their young in colonies that may include over 20000 individuals. The ponds or lakes associated with these colonies are on one hand provided with enhanced nutrients making them Arctic oases, while on the other hand they are contaminated with biomagnifying industrial organochlorine compounds at rates that far exceed the atmospheric delivery.

\subsection{Mobilization of contaminants due to thawing permafrost}

Human activities in remote cold regions lead to the production of waste and the release of anthropogenic contaminants into surrounding ecosystems. The Arctic regions are more vulnerable than those in Antarctica to such sources given the resident populations and the location of industry, especially in the Eurasian north (AMAP, 1998), and in terms of extraction of resources from the continental shelves (e.g., oil and gas recovery). Given the lack of these sorts of sources in Antarctica, and that most industrial/agricultural sources are in the Northern Hemisphere, Antarctic biosystems are considered minimally impacted by primary sources of contaminants. Today, regulations under the Antarctic Treaty prevent industrial and some tourist-related activities on the continent.

For many Arctic settlements in regions of permafrost, historical containment of wastes has depended in one way or an- other on the advantage of containment by permafrost (ACIA, 2005). Waste handling in the form of sewage lagoons, dumpsites at military installations and solid waste dumps in small communities and industrial installations (i.e., oil-drilling sumps) continues to the present (Macdonald et al., 2005). Waste disposal in landfills and dumpsites is a potential local source of POPs and has received significant attention in the case of PCBs associated with the distant early warning sites ("DEW-line") across Arctic Canada (e.g., Brown et al., 2009). Recently, PBDEs have been measured in soils around dumpsites in Cambridge Bay and Iqaluit in Arctic Canada. Concentrations in landfill soils were, in some cases, over 100-fold higher than concentrations measured in background soils, thereby presenting a significant local source of these persistent chemicals (Danon-Schaffer et al., 2008). Permafrost thawing would result in enhanced transport of leachates and associated contaminants away from these sites, promoting input to aquatic systems in close proximity to major Arctic communities. In Canada, climate change has been considered during the development/approval of wastecontainment infrastructures for the past ten years (AMAP, 2011).

Although far more remote from highly-industrialized countries than Arctic regions, the Antarctic also receives POPs (Tanabe et al., 1983; Bargagli, 2008). Large international research stations along the Antarctic coast have been identified as significant local POP contamination sources (Risebrough et al., 1990; Choi et al., 2008), but strict handling protocols for waste in Antarctica minimize this source. As in the case of the Arctic, potential challenges may be expected from contaminant reservoirs contained in or by ice and snow (secondary sources) and the release of these contaminants due to permafrost and ice cover reduction (Curtosi et al., 2007; Mayewski et al., 2009; Aronson et al., 2011).

\subsection{Photodegradation of contaminants in ice and snow}

While the physical processing of contaminants in ice/snow is critical in determining their cryospheric fate, field and laboratory investigations have unambiguously demonstrated that organic compounds can undergo chemical changes in ice or snow (Klán and Holoubek, 2002; Grannas et al., 2007a; McNeill et al., 2012; Bartels-Rausch et al., 2012). Subsequent release of the products may significantly impact the composition and chemistry of the overlying atmosphere or the aquatic environment.

The primary chemical transformations occurring in ice/snow can either be photochemically or thermally initiated. Compounds that absorb solar radiation may undergo $\mathrm{di}$ rect photochemical reaction. If the compounds do not absorb solar radiation they may still react with other species present in snow and ice via secondary (indirect) photochemical processes. It has been shown that $\mathrm{H}_{2} \mathrm{O}_{2}$, nitrate, and organic materials are efficient photosensitizers in sunlit snow and ice (see for example Jacobi et al., 2006; Ram and Anastasio, 
2009; Beine et al., 2012). Dark reactions of organic compounds may also occur, but typically only with the most chemically reactive substances such as radicals (e.g. OH), or reactive oxygen species (e.g. $\mathrm{O}_{3}$ ).

The likelihood and course of a photochemical reaction depends on many factors, including the optical, photophysical, and chemical properties of the chromophores (lightabsorbing species); the optical and phase properties of the host matrix (ice/snow); the presence of potential photosensitizers; and temperature (Grannas et al., 2007a and references therein; Kahan and Donaldson, 2007; Ram and Anastasio, 2009; Kahan and Donaldson, 2010; Kahan et al., 2010; Heger et al., 2011; Kurková et al., 2011). We are far from a comprehensive understanding of snow photochemistry, due to a variety of difficulties associated with preparing adequate snow and ice mimics in a controlled laboratory setting. These challenges are discussed in further detail below.

One phenomenon that has been hypothesized to play an important role in snow and ice chemistry (for both photochemical and thermal reactions) is the freeze-concentration effect. Freezing of aqueous solutions of organic compounds results in substantial increased local concentrations of solutes at the ice/air interface and in micropockets within the bulk ice (Heger et al., 2005). This process can impact both the mechanisms of reaction and the rate of reaction. For example, in areas of high solute concentration rates of bimolecular reactions can be enhanced (Grannas et al., 2007b) and reaction mechanisms may change due to increased probability of coupling reactions over solvolysis (Klánová et al., 2003b). Reactions are also feasible within the bulk ice as well as at interfaces (Ruzicka et al., 2005). Species may also deposit on an ice surface from the gas phase, which leads gradually to the formation of a monomolecular layer (Heger et al., 2011; Kurkova et al., 2011; Ray et al., 2011). The recent review of McNeill et al. (2012) describes in more detail the molecularlevel aspects of organic solutes and their chemistry in environmental ices.

The incorporation of organics into snow and ice may influence their photochemical fate, as the absorption spectra of chromophores in liquid water do not necessarily coincide with those of the same substances in/on ice. This is because of specific substance-ice or substance-substance interactions that may occur in/on ice (Heger and Klán, 2007) or altered acid/base properties caused by the freezing process (Heger et al., 2006). For example, the spectra of simple aromatic compounds, such as phenol derivatives (Matykiewiczova et al., 2007b) or benzene (Kahan and Donaldson, 2010), exhibit bathochromic shifts to wavelengths that overlap with those of solar radiation reaching the Earth's surface, making the likelihood of photochemical degradation in environmentally relevant frozen matrices greater.

Laboratory studies have raised the question of whether potential chromophoric organic contaminants, deposited in polar snowpacks or adsorbed on ice crystals in the atmosphere and exposed to solar irradiation, can produce envi- ronmentally hazardous photoproducts, which may later be introduced into the environment via melting or evaporation processes. Studies have been reported for species such as halogenated aromatic compounds (e.g., chlorobenzenes, chlorophenols, PCBs) (Klán et al., 2000a, b, 2001; Klánová et al., 2003b; Literak et al., 2003; Dolinova et al., 2006; Matykiewiczova et al., 2007b), nitroaromatic compounds (Dubowski and Hoffmann, 2000), or organophosphorus compounds (Weber et al., 2009). However, these experiments employed frozen aqueous solutions as ice mimics with relatively high initial reactant concentrations $\left(>10 \mu \mathrm{g} \mathrm{kg}^{-1}\right)$; contaminant concentrations in natural snow are considerably lower on the order of $10 \mathrm{ng} \mathrm{kg}^{-1}$ or less (Grannas et al., 2007a).

It has been shown that reaction mechanisms in snow/ice can be significantly different than what would occur in a liquid aqueous sample. Photolysis of frozen solutions of haloarenes at or below $-7^{\circ} \mathrm{C}$ gave predominately reductive dehalogenation and coupling products, instead of photosolvolysis products, which are formed in irradiated liquid aqueous solutions (Klán et al., 2000a, 2001; Klánová et al., 2003b) (Fig. 9). Predominant formation of the coupling products has been shown to be related to the freeze concentration effect (Heger et al., 2005) and efficient diffusion of reactive intermediates (Ruzicka et al., 2005). The specific course of the reaction is then related to the fact that water molecules of ice do not act as nucleophiles (Klánová et al., 2003b). When chlorophenols and hydrogen peroxide (as a source of the $\mathrm{OH}$ radicals upon photolysis) or inorganic nitrates (a source of $\mathrm{NO}_{\mathrm{x}}$ and $\mathrm{OH}$ radicals) are irradiated in frozen aqueous solutions, oxidation/nitration reactions compete with the photolysis (Klánová et al., 2003a; Matykiewiczova et al., 2007b). In contrast, some compounds, such as 4nitrophenol (Dubowski and Hoffmann, 2000), were found to give the same photoproducts in both liquid and frozen samples. In cases where different products are produced due to chemistry in snow/ice, it will be important to assess their toxicity and bioaccumulation potentials, as these may be quite different than the products formed from gas phase or aqueous (liquid) chemistry. For example, the toxic effects of chlorobiphenyldiols formed upon the photolysis of 2- and 4chlorophenol in frozen aqueous solutions were evaluated using a bacterial luminescence test and in vitro biomarker assay for dioxin-like effects, and compared to those manifested by product formation in the liquid aqueous solutions (dihydroxybenzenes) (Blaha et al., 2004). Contrary to the aqueous solutions, the irradiated ice samples elicited significant inductions of dioxin-like effects. The authors concluded that the photochemistry can have an unexpected impact to pristine polar regions, when organic contaminants are present in ice/snow as trace constituents.

Low concentrations of snow contaminants and the complexity of the system are great challenges to those who want to study the physical and chemical processes occurring in natural snow. Investigations of ice surface/air exchange and photochemical processes of hydrophobic organic compounds 


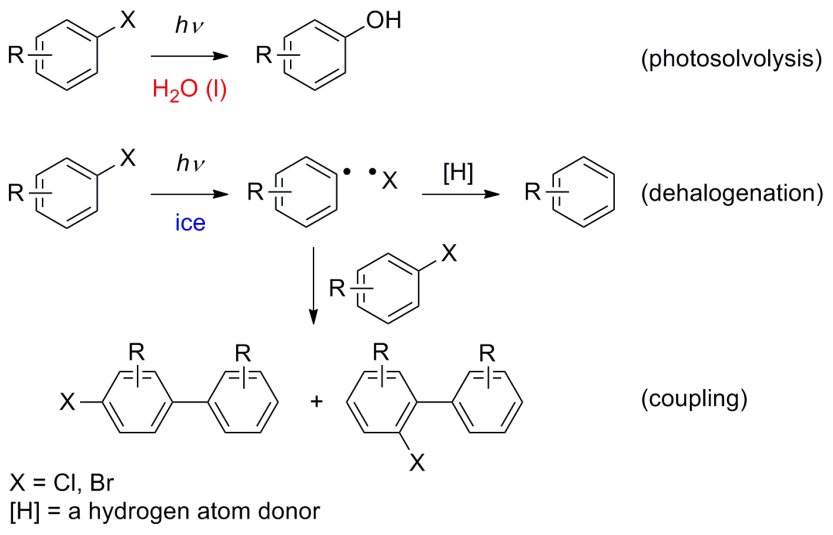

Fig. 9. Comparison of photochemistry of haloarenes in water and frozen aqueous solutions, illustrating the different mechanisms and products that occur in liquid water and ice.

have been carried out using ice grains (artificial "snow") (Matykiewiczova et al., 2007a; Heger et al., 2011; Kurkova et al., 2011; Ray et al., 2011). This snow is produced by a shock-freezing preparation technique either as pure snow (which is then exposed to vapors of an organic compound), or as contaminated snow prepared directly from the corresponding aqueous solutions (Matykiewiczova et al., 2007a; Heger et al., 2011; Kurkova et al., 2011; Ray et al., 2011). The specific surface coverage of artificial snow grains by hydrophobic organic compounds has been estimated with the help of a photofragmentation process (Heger et al., 2011; Kurkova et al., 2011) or ozonation reaction (Ray et al., 2011). A remarkable and unexpected increase in the apparent ozonation rates of 1,1-diphenylethylene at the air-ice interface with decreasing temperature was reported recently (Ray et al., 2013). It was suggested that an increase of the number of surface reactive sites, and possibly higher ozone uptake coefficients are responsible for the apparent rate acceleration. Even in the case of ice surface loadings which correspond to submonolayer coverages, some organic compounds tend to selfassociate on the ice/snow surface (Kahan and Donaldson, 2007, 2010; Heger et al., 2011; Kurkova et al., 2011). Therefore, intramolecular as well as intermolecular (substancesubstance or substance-gaseous reactant) chemical processes are likely to occur on the ice surfaces.

A laboratory study of the photochemical behavior of POPs, such as PCBs, in artificial snow at environmentally relevant concentrations enabled simultaneous monitoring of their photochemical changes and volatilization fluxes from the solid matrix (Matykiewiczova et al., 2007a). Reductive dehalogenation (Fig. 9), as the major degradation pathway, competed with a desorption process responsible for the contaminant loss from snow. It has been estimated that the lifetime of PCBs in snow under solar radiation at $-25^{\circ} \mathrm{C}$, connected exclusively to this process, is $1-2$ orders of magnitude longer than that in surface water. However, in cases where sufficient amounts of hydrogen peroxide (a photochemical $\mathrm{OH}$ radical source) are present in snow, photoinduced oxidation processes could surpass both photoreductive dechlorination and evaporative losses of PCBs as the major sink in a sunlit snowpack (Matykiewiczova et al., 2007a).

While the majority of reported studies have been conducted in laboratory settings, several studies conducted in the field also point to the potential importance of photochemical degradation of contaminants in/on snow and ice surfaces. Klán et al. (2003) demonstrated that several aromatic carbonyl, chloro, nitro and hydroxyl compounds underwent very efficient sunlight-induced chemical reaction in experiments conducted using ice samples prepared from clean water, but irradiated in natural sunlight in Svalbard, Arctic Norway. The observed photoproducts could pose a high toxicological risk to biota if they entered the environment. Rowland et al. (2011) studied the photochemical degradation of several organochlorine compounds via both direct photodegradation as well as photosensitizer induced reaction during field experiments conducted in Barrow, Alaska in 2008. Interestingly, samples made using snow collected from the Barrow area showed the greatest reactivity (when compared to several control experiments), and the authors hypothesized that natural organic matter present in the snowpack could be an important photosensitizer for environmental photochemical reactions in snow/ice. This result is in agreement with the recent report of Beine et al. (2012) which indicates that chromophoric dissolved organic matter is the dominant source of reactive $\mathrm{OH}$ radicals in Barrow area snow, ice and frost flowers.

Controlled laboratory studies relying on experimental ice mimics are often confronted with challenges such as instrumental limits of detection and sample size or extraction volume limits which preclude the use of samples made using environmentally relevant concentrations. It has been argued by Guzman et al. (2007) that although natural and laboratory ices certainly differ in many ways, the important component is the "molecular domains sensed by the solutes themselves, rather than the macroscopic/mesoscopic ice textures and morphologies perceived by observers...". They argue that in both cases (lab-generated and natural samples) the local concentrations in the microscopic ice domains where the chemistry occurs are greatly elevated relative to the bulk (melted) solute concentration due to the freeze concentration effect, and as such, ice mimics are relevant substitutes for environmentally-formed snow/ice. On the other hand, the generation of ice mimics in the laboratory (typically obtained by freezing liquid water samples containing the target solute for study and perhaps also relevant photosensitizers) certainly do not reproduce the typical environmental snow crystal formation mechanism (except perhaps for riming, as described in Sect. 3.1). Few reactivity studies have been made on ice condensed from the gas phase, which is how most natural snow forms. While it is easier to make ice of a given bulk composition by freezing liquid water than by 
condensing vapor, techniques have been proposed to make snow by condensing water vapor (Loewe et al., 2011). Additionally, the potential physical and chemical interactions of solutes in liquid-like/disordered interfaces with particulate matter co-located in these domains have not been addressed. For example, particulate organic matter could serve as a photosensitizer, could impact the air/surface partitioning of solutes via sorption, or could shield solutes from photochemical reaction due to light screening effects. Although these effects could significantly impact snow photochemistry processes, none of these have been evaluated in laboratory-based studies. As discussed initially in Grannas et al. (2007a), the community still lacks a comprehensive understanding of the incorporation of impurities into environmental snow and ice, and their chemical morphology at both macroscopic and microscopic scales. This currently serves as a barrier to the potential extrapolation of laboratory experimental results to the environmental realm. Given the chemical complexity of snow/ice in the environment, and the various ways in which species may be incorporated into the snow/ice matrix, it will be a challenging, but vitally important, effort to elucidate the various chemical mechanisms at play at the molecular level.

\subsection{Comparison of contaminant/cryosphere interactions in different environments}

Various interactions between contaminants and the cryosphere have been described in Sects. 3.1-3.9. Each cryospheric compartment plays a unique role in influencing contaminant transport and fate. It should be noted that these interactions may be very different depending on the environment. For example, as discussed in Halsall (2004), snow-atmosphere chemical exchange will in large part be controlled by the evolution of SSA. The physical processes controlling SSA will be quite different in, for example, the high Arctic as compared to warmer sub-arctic areas. In the Arctic, low precipitation amounts and frequent windstorms during winter result in the surface snow being shaped by repeated wind events, rather than numerous fresh snowfall events. This results in a hard wind-packed snow, with the surface dominated by sastrugi, with relatively shallow depth. In contrast, sub-arctic snow tends to exhibit lower density and SSA, higher depths, higher permeability and is exposed to lower wind speeds and higher temperatures. These variables will certainly affect snow-atmosphere transfer, as discussed in Sect. 3.2.

An additional factor influenced by the local environment is the snowmelt process. As discussed in Sect. 3.3, the springtime contaminant "pulse" observed in receiving waters depends in part on the extent of ground infiltration and surface run-off. Additionally, the early elution of water soluble compounds was found to be most pronounced in deep and aged snowpack that is melting rapidly, while it is attenuated in layered snow with hydraulic barriers and in snowpacks that are subject to bottom melt. Thus, it is crucial that lab or field-based studies investigating contaminant fate consider not only the physicochemical properties of the contaminants, but also the physical nature and evolution of a snowpack over the timescale of the process being studied.

Another comparison can be made at the large scale between sea ice produced in the Arctic Ocean and in the Southern Ocean. For the former, the ice generally accretes by freezing at the bottom while a relatively small snow load is accumulated at the top of the ice due to the desert-like conditions of the Arctic (e.g. Serreze et al., 2006). For much of the Arctic's ice these large-scale circumstances allow us to infer generality from the relatively few detailed studies of contaminants in ice reviewed above. In the Southern Ocean, sea ice initially forms in much the same way, accreting new ice at the bottom. However, a substantially larger snow loading favors flooding of the sea ice with seawater, which then freezes together with the snowpack to form layers at the top of the ice (Lange et al., 1990). We know nothing about how the flooding of snow-covered ice affects contaminant distributions and the subsequent entry of these contaminants into marine ecosystems. It is, however, clear that general conclusions based on studies of un-flooded sea ice cannot be extended to ice that has been flooded. Within the Arctic Ocean itself, sea-ice flooding is known to occur in coastal regions prone to storm surges (Carmack and Macdonald, 2008).

\section{Knowledge gaps and research needs}

There are currently several knowledge gaps and research needs that limit our understanding of contaminant fate and the potential impact of climate change on contaminant transport and processing. These include challenges related to field, laboratory and modeling studies. Adequate consideration of these issues will require interdisciplinary studies at a variety of scales, from molecular level processes to global transport studies.

\subsection{Experimental challenges}

As discussed in Sect. 3.9, creating appropriate snow and ice mimics in the laboratory environment can be challenging. We do not have a clear understanding of how the method of sample generation might impact the location of contaminants or photosensitizers within the snow or ice sample, and how in turn the observed reactivity or partitioning equilibria observed in a laboratory experiment might be influenced by the sample preparation method. Efforts should be made to conduct laboratory experiments on snow mimics created from condensing water vapor, rather than freezing of liquid solutions. No studies have quantitatively addressed the role of organic or mineral particles within/on ice under controlled laboratory conditions, even though these surfaces likely play an important role in contaminant reactivity in environmentally 
relevant ices. The development of adequate sample preparation techniques is a non-trivial issue for experimentalists.

Another great challenge of studying contaminant fate in the cryosphere is the very large heterogeneity of snow and ice on both a spatial and temporal scale and how this may impact contaminant fate. Laboratory experiments on contaminant behavior in melting snow have proven useful in gaining important mechanistic insights and in facilitating a quantitative description of contaminant fate during snowmelt. Other contaminant fate processes related to the cryosphere may be amenable to similar approaches relying on a set of highly controlled and reproducible experimental conditions within a cold room. Examples include:

- Contaminant fate during sea ice formation, growth and melting, including the fate of contaminants from snowpacks accumulating and melting on top of ice,

- Air-snow exchange of contaminants and its dependence on snow permeability and wind conditions,

- Mobility, reactivity, and potential for redistribution of contaminants in firn and glacier ice, in particular during time periods of seasonal melting,

- Photochemical, microbial and other transformation processes of contaminants in snow.

Ultimately, comprehensive field experiments, like those initiated for HCH by Pućko et al. (2011a, b) should incorporate a more complete set of fate processes affecting contaminants in a snowpack or in sea ice simultaneously and may become feasible (i.e. experiments that investigate the interaction between contaminant reactions, redistribution and loss by melt water or brine, and in the vapor phase, and how these interactions are governed by snowpack/ice characteristics, chemical properties, and meteorological conditions). Another possibility is a hybrid approach, where environmental snow/ice samples are transferred to a cold-room to conduct experiments under controlled and reproducible conditions, thereby avoiding the question to what extent artificial snow/ice samples are representative of the real environment.

Assessment of spatial and temporal trends of contaminants in snow and ice is complicated by post-depositional changes in the snow concentrations, sampling access, potential contamination from local emissions (e.g. field station operations in remote polar locations), and analytical challenges related to detecting low-levels of contaminants and potential contamination or losses due to sample processing. It has been suggested that the wide range of reported concentrations of organic contaminants in snow can be partly attributed to postdepositional processes. Revolatilization of organochlorines has been shown to take place in response to increases in snow density and decreases in snow surface area (Blais et al., 1998; Herbert et al., 2005b; Finizio et al., 2006; Burniston et al., 2007). Seasonal snowmelt (Gustafsson et al., 2005) and chemical degradation (Hoyau et al., 1996) are also important factors contributing to within-region variability. Given the variety of laboratory-based studies investigating the chemical degradation of contaminants in snow and ice, it would be informative to identify the observed products in environmental samples. This would help verify the validity of laboratorybased experiments and determine quantitatively the importance of these reactions in the environmental setting.

Gas-particle partitioning is an additional factor affecting the behavior of organic compounds in cold environments. Assessment of snow/ice concentrations of contaminants and their association with the particle phase is difficult. Snow and ice samples must be melted prior to analysis, and this will likely result in a redistribution of dissolved and particlephase contaminants (Wania et al., 1999b). As such, quantitative assessments of dissolved and particle-phase contaminants in snow and ice should be interpreted with caution. Hageman et al. (2010) quantified spatial and temporal variability in contaminant concentrations in snowpack samples; however, more studies designed to assess the various sources of variability in snow and ice samples are needed and this is best done with long-term and high-resolution sample analysis. Unfortunately, the ability to conduct such large scale monitoring efforts is hampered by the large sample sizes typically required for snow/ice analysis and the careful and time-consuming sample preparation and analysis process. Thus, the development of analytical techniques that can increase sensitivity and decrease interferences would allow for smaller sample sizes and open the door to higher spatial and temporal resolution studies.

\subsection{Validation and improvement of models}

Although contaminant pulses resulting from spring snowmelt have been predicted from modeling and lab studies (reviewed in Meyer and Wania, 2008) and observed in the field in a few cases (Lafrenière et al., 2006; Bizzotto et al., 2009a; Meyer et al., 2011a, b), more field studies are needed to determine how common and how important this phenomenon is. For example, we need to better understand how different environmental conditions affect snowmelt-induced contaminant pulses, especially by comparing field and modeling results. We also need to identify the types of mountain and polar systems and locations in the world that might be most prone to snowmelt-induced contaminant pulses. Moreover, more studies need to be conducted to determine the likelihood and degree to which snowmelt-induced contaminant pulses are causing biological impacts (i.e. extension of the work by Bizzotto et al., 2009b) and to identify which aquatic organisms might be most affected. These types of studies will require increasing collaboration between chemists and ecologists/ecotoxicologists. Additionally, the importance of contaminant exposure via snowmelt should be compared to that arising from other sources of contaminant exposure. Similarly, more field and modeling studies need to be conducted to determine the degree to which the release of contaminants 
from melting glaciers may cause biological impacts. It will be important to differentiate contaminant releases due to the melting of seasonal snowpack versus those due to climate change induced glacier melt. Likewise, it will be important to understand if contaminants in polar marine systems predominantly come from melting glaciers, sea ice, sea snowpack or directly from the atmosphere.

One advance that will aid in modeling efforts is the $\mathrm{Eu}-$ ropean Space Agency Cryosat-2 mission. Cryosat-2 was launched in 2010 with the goal of monitoring changes in the thickness and extent of polar ice. Recent reports indicate that Cryosat is delivering an unprecedented view of the seasonal growth and retreat of sea ice across the Arctic, as well as information on the thickness of the Greenland ice sheet, accurate to within 10-20 cm (Parrinello et al., 2012). This information will be a critical component in models that attempt to quantify the role of melting sea ice/glaciers on contaminant fate. A better understanding of the overall fate of the cryosphere is of great importance for modeling the potential fate of contaminants contained within various cryospheric compartments.

While modeling should continue and increasingly be used to understand the role of the cryosphere in contaminant fate processes, input values still need improvement. In particular, snow-air and snow-ice partition coefficients need to be measured for a larger set of chemicals than currently available (Hoff et al. 1995; Roth et al. 2004). Although estimation methods for these partition coefficients exist (Roth et al., 2004), they may not be appropriate for more complicated chemicals such as current-use pesticides and some of the semi-volatile emerging contaminants. Additionally, many equilibrium estimation methods result in bulk sorption parameters, but give little detail about the actual mechanism of uptake. For example, quantification of contaminant interactions with particulate matter in snow would aid not only modelers, but also those interested in potential chemical interactions that may occur when organic materials act as photosensitizers.

\subsection{Logistics and community coordination}

For many of the POPs, we have few or no reliable ocean data collected as depth profiles or along transects from shelf to basin interior locations. These sorts of profiles are crucial to obtain an accurate assessment of contaminant distribution, storage by the upper ocean and the state of equilibrium between ocean and atmosphere. Presently, there are few ice-breakers capable of doing such work (requirements include ice capability plus clean laboratory and sampling facilities plus ancillary geochemical/instrumental profiling). Some Arctic countries (USA, Canada) face the issue of aging icebreakers that will require years to bring replacements on line (NRC, 2011). Recently there have been opportunities to collect appropriate, year-round data at field camps from which contaminant processes can be inferred. For example, the CFL project overwintered the Canadian Coast Guard icebreaker Amundsen in the Beaufort Sea providing facilities and time to conduct a variety of contaminant measurements on snow, ice, water and biota (e.g., Pućko et al., 2010a, b; Codling et al., 2012). However, these opportunities are rare and require expensive commitments in logistics. Because the scientific community currently faces increasingly limited resources, it is crucial that we effectively communicate key research priorities and work collaboratively to make efficient use of the available opportunities and field research platforms. Additionally, the contaminant research community does work at a variety of scales, from experiments aimed at a molecularlevel understanding of chemical degradation to modeling of atmospheric transport at the global scale. Interdisciplinary collaboration and communication is critical to link the various individual studies done at multiple scales in a meaningful and accurate manner.

Opportunities should be sought to extend collaboration between the science community and the people who live in cold regions. One immediate benefit is the potential to engage local communities in monitoring activities, which otherwise could be prohibitively expensive. Collaboration then leads to better monitoring design by incorporating local knowledge, and better communication between scientists and local communities. The scientific community should also actively engage policymakers and industry. Energy development activities are expanding in polar regions and new transportation routes will open as sea ice retreats, both of which will impact contaminant sources. It will be critical to actively engage the parties making and enforcing regulatory decisions or industrial practices, in efforts to reduce the introduction of contaminants into sensitive polar ecosystems.

\section{Conclusion}

The cryosphere has the capacity to significantly impact the local, regional and global cycling of contaminants. Field, laboratory, and modeling studies have shown that snow and ice are crucial components of the Earth system that can influence the fate of contaminants, through both uptake and release mechanisms. Chemical processes occurring in snow and ice may also impact contaminant fate, in some cases generating products potentially more toxic or more bioaccumulative than the original contaminant. The scientific community has made much progress in elucidating the mechanisms of contaminant transport and redistribution within the cryosphere, and how these may be impacted by a changing climate.

The effects of climate change are becoming more pronounced in the cryosphere, evidenced for example by unprecedented declines in sea ice extent. Climate-induced changes to the cryosphere will certainly impact the fate of contaminants, altering atmospheric and oceanic transport and releasing previously trapped contaminants from melting ice and glaciers. There remain many unanswered questions 
regarding the impact of climate change on cryospheric contaminant cycles. For example, recent winter warming anomalies in the Arctic are resulting in rapid temporary thawing events resulting in partial melt of the winter snowpack and the exposure of the underlying tundra vegetation (e.g. Olsen et al., 2011; Callaghan et al., 2011). This is often followed by the subsequent formation of sheet-ice once temperatures decline again. The ecological implications of these events on terrestrial flora and fauna are the subject of ecological research (e.g. Bokhorst et al., 2011) but the release and fate of contaminants from the seasonal snowpack and their potential impact as additional stressors during these types of event are currently unknown.

The greening of the Arctic will likely impact air/surface exchanges, may increase forest/tundra fire frequency, and could lead to remobilization of contaminants associated with plant and soil carbon. In addition to climate change impacts, the expanding development of the Arctic may have a large future impact on organic contaminant levels and trends within the region, as energy resource exploration expands and waterways open to shipping traffic. Contaminants interact with the cryosphere in varied and complex ways, involving the interplay of biological, chemical, and physical processes. Although these are often studied as isolated processes, it is crucial to develop an interdisciplinary picture of contaminant cycling, which will require effective communication across multiple disciplines.

\section{Appendix A}

List of abbreviations used

ACCE: Antarctic Climate Change and the Environment

ACIA: Arctic Climate Impact Assessment

AMAP: Arctic Monitoring and Assessment Programme

CFL: Circumpolar Flaw Lead

CLRTAP: Convention on Long-Range Transboundary Air Pollution

DBA: 2,4-dibromoanisole

DEW: Distance early warning

DDT: Dichlorodiphenyltrichloroethane

EF: Enantiomeric Fraction

GMP: Global Monitoring Plan

HCH: Hexachlorocyclohexane

IPCC: Intergovernmental Panel on Climate Change

ISCAR: International Scientific Committee on Research in the Alps
LRAT: Long-range atmospheric transport

MIZ: Marginal ice zone

MTC: $\quad$ Mass transfer coefficient

NCP: $\quad$ Northern Contaminants Program

PAH: Polycyclic Aromatic Hydrocarbon

PBDE: Polybrominated diphenylether

PCB: $\quad$ Polychlorinated biphenyl

PCDD/Fs: Polychlorinated dibenzo- $p$-dioxins and dibenzofurans

PFCA: Perfluorocarboxylic acid

POP: Persistent Organic Pollutant

SSA: $\quad$ Specific Surface Area (snow)

TBA: 2,4,6-tribromoanisole

UNECE: United Nations Economic Commission for Europe

UNEP: United Nations Environment Programme

Acknowledgements. This manuscript arose from discussions during and following the 3rd Workshop on Air-Ice Chemical Interactions (AICI) in June 2011, in New York, NY. This workshop was sponsored in part by IGAC and the Columbia University School of Engineering and Applied Sciences. We wish to acknowledge IGAC for financial support for publication costs. A. M. G. wishes to acknowledge support from the NSF CAREER award (ATM0547435). P. K. wishes to acknowledge support from the Grant Agency of the Czech Republic (P503/10/0947), and the project CETOCOEN (CZ.1.05/2.1.00/01.0001) granted by the European Regional Development Fund. The comments and suggestions of three reviewers are gratefully acknowledged.

Edited by: T. Bartels-Rausch

\section{References}

Åberg, A., MacLeod, M., and Wiberg, K.: Physical-chemical property data for dibenzo-p-dioxin (DD), dibenzofuran (DF), and chlorinated DD/Fs: A critical review and recommended values, J. Phys. Chem. Ref. Data, 37, 1997, 2008.

Abbatt, J. P. D., Thomas, J. L., Abrahamsson, K., Boxe, C., Granfors, A., Jones, A. E., King, M. D., Saiz-Lopez, A., Shepson, P. B., Sodeau, J., Toohey, D. W., Toubin, C., von Glasow, R., Wren, S. N., and Yang, X.: Halogen activation via interactions with environmental ice and snow in the polar lower troposphere and other regions, Atmos. Chem. Phys., 12, 6237-6271, doi:10.5194/acp-12-6237-2012, 2012. 
ACCE: Antarctic Climate Change and the Environment, edited by: Turner, J., Bindschadler, R. A., Convey, P., Di Prisco, G., Fahrbach, E., Gutt, J., Hodgson, D. A., Mayewski, P. A., and Summerhayes, C. P., Scientific Committee on Antarctic Research, Cambridge, 526 pp., 2009.

ACIA, Arctic Climate Impact Assessment, Cambridge University Press 2005, 1042 pp., 2005.

Albert, M. R. and Hawley, R. L.: Seasonal changes in snow surface roughness characteristics at Summit, Greenland: implications for snow and firn ventilation, Ann. Glaciol., 35, 510-514, 2002.

Albert, M. R. and Shultz, E. F.: Snow and firn properties and transport processes at Summit, Greenland, Atmos. Environ., 36, 2789-2797, 2002.

Albert, M. R., Shultz, E. F., and Perron Jr., F. E.: Snow and firn permeability at Siple Dome, Antarctica, Ann. Glaciol., 31, 353356, 2000.

Albert, M. R., Grannas, A. M., Bottenheim, J., Shepson, P. B., and Perron, F. E.: Processes and properties of snow-air transfer in the high Arctic with application to interstitial ozone at Alert, Canada, Atmos. Environ., 36, 2779-2787, 2002.

AMAP Assessment 1998: Arctic Pollution Issues, Arctic Monitoring and Assessment Programme, Oslo, Norway, 859 pp., 1998.

AMAP Assessment 2005: Arctic Climate Impact Assessment, Arctic Monitoring and Assessment Programme, Oslo, Norway, 1020 pp., 2005.

AMAP Assessment 2009: Assessment of Persistent Organic Pollutants in the Arctic. Oslo, Norway: Arctic Monitoring and Assessment Programme, Oslo, Norway. 83 pp., 2009a.

AMAP Assessment 2009: The Greenland Ice Sheet in a Changing Climate: Snow, Water, Ice and Permafrost in the Arctic (SWIPA) 2009edited by: Dahl-Jensen, D., Bamber, J., Bøggild, C. E., Buch, E., Christensen, J. H., Dethloff, K., Fahnestock, M., Marshall, S., Rosing, M., Steffen, K., Thomas, R., Truffer, M., van den Broeke, M., and van der Veen, C. J., Arctic Monitoring and Assessment Programme (AMAP), Oslo, Norway. 115 pp., $2009 b$.

AMAP Assessment 2011: Snow, Water, Ice and Permafrost in the Arctic (SWIPA): Climate Change and the Cryosphere, Arctic Monitoring and Assessment Programme (AMAP), Oslo, Norway, xii, 538 pp., 2011 a.

AMAP Assessment 2011: Combined Effects of Selected Pollutants and Climate Change in the Arctic Environment, edited by: Kallenborn, R., Borgå, K., Christensen, J. H., Dowdall, M., Odland, J. Ø., Ruus, A., Aspmo Pfaffhuber, K., Pawlak, J., and Reiersen, L.-O., Arctic Monitoring and Assessment Programme (AMAP), Oslo, Norway, 109 pp., 2011 b.

Armitage, J. M., Quinn, C.L., and Wania, F.: Global climate change and contaminants - an overview of opportunities and priorities for modelling the potential implications for long-term human exposure to organic compounds in the Arctic, J. Environ. Monit. 13, 1532-1546, 2011.

Armstrong, R. L. and Brodzik, M. J.: Recent northern hemisphere snow extent: A comparison of data derived from visible and microwave satellite sensors, Geophys. Res. Lett., 28, 3673-3676, 2001.

Aronson, R. B., Thatje, S., McClintock, J. B., and Highes, K. A.: Anthropogenic impacts on marine ecosystems in Antarctica, Ann. NY Acad. Sci., 1223, 82-107, 2011.
Ashauer, R., Wittmer, I., Stamm, C., and Escher, B. I.: Environmental risk assessment of fluctuating diazinon concentrations in an urban and agricultural catchment using toxicokinetictoxicodynamic modeling, Environ. Sci. Technol., 45, 97839792, 2011.

Bailey, R. E.: Global hexachlorobenzene emissions, Chemosphere, 43, 167-182, 2001.

Barber, J. L., Sweetman, A. J., van Wijk, D., and Jones, K. C.: Hexachlorobenzene in the global environment: Emissions, levels, distribution, trends and processes, Sci. Total Environ., 349, 1-44, 2005.

Bard, S.: Global transport of anthropogenic contaminants and the consequences for the Arctic marine ecosystem, Mar. Pollut. Bull., 38, 356-379, 1999.

Bargagli, R.: Environmental contamination in Antarctic ecosystems, Sci. Total Environ., 400, 212-226, 2008.

Barrie, L. A., Gregor, D., Hargrave, B., Lake, R., Muir, D., Shearer, R., Tracey, B., and Bidleman, T.: Arctic contaminants: sources, occurrence and pathways, Sci. Total Environ., 122, 1-72, 1992.

Barrie, L. A., Macdonald, R. W., Bidleman, T., Diamond, M., Gregor, D., Semkin, R., Strachan, W., Alaee, M., Backus, S., Bewers, M., Gobeil, C., Halsall, C., Hoff, J., Li, Y. F., Lockhart, L., Mackay, D., Muir, D., Pudykiewicz, J., Reimer, K., Smith, J., Stem, G., Schroeder, W., Wagemann, R., Wania, F., and Yunker, M.: Chapter 2. Sources, occurrence and pathways, edited by: Jensen, J., Adare, K. and Shearer, R., in: Canadian Arctic Contaminants Assessment Report, Department of Indian and Northern Affairs, Ottawa, 25-182, 1997.

Barrie, L. A., Falck, E., Gregor, D., Iverson, T., Loeng, H., Macdonald, R., Pfirman, S., Skotvold, T., and Wartena, E.: The influence of physical and chemical processes on contaminant transport into and within the Arctic, edited by: Gregor, D., Barrie, L., and Loeng, H., in: The AMAP Assessment, 25-116, 1998.

Bartels-Rausch, T., Jacobi, H.-W., Kahan, T. F., Thomas, J. L., Thomson, E. S., Abbatt, J. P. D., Ammann, M., Blackford, J. R., Bluhm, H., Boxe, C., Domine, F., Frey, M. M., Gladich, I., Guzmán, M. I., Heger, D., Huthwelker, Th., Klán, P., Kuhs, W. F., Kuo, M. H., Maus, S., Moussa, S. G., McNeill, V. F., Newberg, J. T., Pettersson, J. B. C., Roeselová, M., and Sodeau, J. R.: Relationship between snow microstructure and physical and chemical processes, Atmos. Chem. Phys. Discuss., 12, 3040930541, doi:10.5194/acpd-12-30409-2012, 2012.

Batterbee, R. W., Kernan, M., and Rose, N.: Threatened and stressed mountain lakes of Europe: Assessment and progress, Aquat. Ecosyst. Health Manage., 12/2, 118-128, 2009.

Becker, S., Halsall, C. J., Tych, W., Kallenborn, R., Schlabach, M., and Man $\varnothing$, S.: Changing sources and environmental factors reduce the rates of decline of organochlorine pesticides in the Arctic atmosphere, Atmos. Chem. Phys., 12, 4033-4044, doi:10.5194/acp-12-4033-2012, 2012.

Beine, H., Anastasio, C., Domine, F., Douglas, T., Barret, M., France, J., King, M., Hall, S. R., and Ullmann, K.: Soluble chromophores in marine snow, seawater, sea ice and frost flowers near Barrow, Alaska, J. Geophys. Res., 117, D00R15, doi:10.1029/2011JD016650, 2012.

Bergknut, M., Laudon, H., Jansson, S., Larsson, A., Gocht, T., and Wiberg, K.: Atmospheric deposition, retention, and stream export of dioxins and PCBs in a pristine boreal catchment, Environ. Pollut., 159, 1592-1598, 2011. 
Bidleman, T. F. and Falconer, R. L.: Using pesticide enantiomers to trace pesticide emissions, Environ. Sci. Technol., 33, 206A209A, 1999.

Bizzotto, E. C., Villa, S., Vaj, C., and Vighi, M.: Comparison of glacial and non-glacial-fed streams to evaluate the loading of persistent organic pollutants through seasonal snow/ice melt, Chemosphere, 74, 924-930, 2009a.

Bizzotto, E. C., Villa, S., and Vighi, M.: POP bioaccumulation in macroinvertebrates of alpine freshwater systems, Environ. Pollut., 157, 2192-3198, 2009b.

Blaha, L., Klánová, J., Klán, P., Janosek, J., Skarek, M., and Ruzicka, R.: Toxicity increases in ice containing monochlorophenols upon photolysis: Environmental consequences, Environ. Sci. Technol., 38, 2873-2878, 2004.

Blais, J. M., Schindler, D. W., Muir, D. C. G., Kimpe, L. E., Donald, D. B., and Rosenberg, B.: Accumulation of persistent organochlorine compounds in mountains of Western Canada, Nature, 395, 585-588, 1998.

Blais, J. M., Schindler, D. W., Sharp, M., Braekevelt, E., Lafreniere, M., McDonald, K., Muir, D. C. G., and Strachan, W. M. J.: Fluxes of semivolatile organochlorine compounds in Bow Lake, a highaltitude, glacier-fed subalpine lake in the Canadian Rocky Mountains, Limnol. Oceanogr., 46, 2019-2031, 2001a.

Blais, J. M., Schindler, D. W., Muir, D. C. G., Sharp, M., Donald, D., Lafrenière, M., Braekevelt, E., and Strachan, W. M. J.: Melting glaciers: A major source of persistent organochlorines to subalpine Bow Lake in Banff National Park, Canada, Ambio, 30, 410-415, 2001b.

Blais, J. M., Macdonald, R. W., Mackay, D., Webster, E., Harvey, C., and Smol, J. P.: Biologically mediated transport of contaminants to aquatic systems, Environ. Sci. Technol., 41, 1075-1084, 2007.

Bogdal, C., Schmid, P., Zennegg, M., Anselmetti, F. S., Scheringer, M., and Hungerbühler, K.: Blast from the past: Melting glaciers as a relevant source for persistent organic pollutants, Environ. Sci. Technol., 43, 8173-8177, 2009.

Bogdal, C., Nikolic, D., Lüthi, M., Schenker, U., Scheringer, M., and Hungerbühler, K.: Release of legacy pollutants from melting glaciers: model evidence and conceptual understanding, Environ. Sci. Technol., 44, 4063-4069, 2010.

Bokhorst, S. F., Bjerke, J. W., Tommervik, H., Callaghan, T. V., and Phoenix, G. K.: Winter warming events damage sub-Arctic vegetation: consistent evidence from an experimental manipulation and a natural event, J. Ecol., 97, 1408-1415, 2009.

Brown, T. M., Sheldon, T. A., Burgess, N. M., and Reimer, K. J.: Reduction of PCB contamination in an Arctic coastal environment: a first step in assessing ecosystem recovery after the removal of a point source, Environ. Sci. Technol., 43, 7635-7642, 2009.

Burniston, D. A., Strachan, W. J. M., Hoff, J. T., and Wania, F.: Changes in surface area and concentrations of semivolatile organic contaminants in ageing snow, Environ. Sci. Technol., 41, 4932-4937, 2007.

Cabanes, A., Legagneux, L., and Domine, F.: Rate of evolution of the specific surface area of surface snow layers, Environ. Sci. Technol., 37, 661-666, 2003.

Cabrerizo, A., Dachs, J., Barcelo, D., and Jonest, K. C.: Influence of Organic Matter Content and Human Activities on the Occurrence of Organic Pollutants in Antarctic Soils, Lichens, Grass, and Mosses. Environ. Sci. Technol., 46, 1396-1405, 2012.

Callaghan, T., Johansson, M., Brown, R., Groisman, P., Labba, N., Radionov, V., Barry, R., Bulygina, O., Essery, R., Frolov, D., Golubev, V., Grenfell, T., Petrushina, M., Razuvaev, V., Robinson, D., Romanov, P., Shindell, D., Shmakin, A., Sokratov, S., Warren, S., and Yang, D.: The changing face of Arctic snow cover: A synthesis of observed and projected changes, Ambio, 40, 17-31, 2011.

Canadian Wind Energy Atlas, EOLE Wind Energy Project, Environment Canada, Quebec, Canada, 2003.

Carmack, E. C. and Macdonald, R. W.: Water and ice related phenomena in the coastal region of the Beaufort Sea: some parallels between native experience and western science, Arctic, 61, 265280, 2008.

Carrera, G., Fernández, P., Vilanova, R. M., and Grimalt, J. O.: Persistent organic pollutants in snow from European high mountain areas, Atmos. Environ., 35, 245-254, 2001.

Carrizo, D. and Gustafsson, Ö.: Distribution and inventories of polychlorinated biphenyls in the polar mixed layer of seven PanArctic shelf seas and the interior basins. Environ. Sci. Technol., 45, 8377-8384, 2011.

Choi, S.D., Baek, S.-Y., Chang, Y.-S., Wania, F., Ikonomou, M.G., Yoon, Y.-J., Park, B.-K., and Hong, S.: Passive air sampling of polychlorinated biphenyls and organochlorine pesticides at the Korean Arctic and Antarctic research stations: Implication for long-range transport and local pollution, Environ. Sci. Technol., 42, 7125-7131, 2008.

Cincinelli, A., Stortini, A. M., Checchini, L., Martellini, T., Del Bubba, M., and Lepri, L.: Enrichment of organic pollutants in the sea surface microlayer (SML) at Terra Nova Bay, Antarctica: influence of SML on superfacial snow composition, J. Environ. Monitor., 7, 1305-1312, 2005.

Clarke, G. K. C. and Waddington, E. D.: A three-dimensional theory of wind pumping, J. Glaciol., 37, 89-96, 1991.

Codling, G., del Vento, S. Stern, G. A.; and Halsall, C. J.: The occurrence of PCBs and OC pesticides in the sea-ice system of the Canadian Arctic: chemical accumulation and fate in the winter marine snowpack, J. Geophys. Res. Ocean., CFL Special Issue, submitted, 2012.

Colbeck, S. C.: Air movement in snow due to windpumping, J. Glaciol., 35, 209-213, 1989.

Corsolini, S., Borghesi, N., Schiamone, A., and Focardi, S.: Polybrominated diphenyl ethers, polychlorinated dibenzo-dioxins, furans, and -biphenyls in three species of Antarctic penguins, Environ. Sci. Poll. Res., 14, 421-429, 2007.

Couillard, C. M., Macdonald, R. W., Courtenay, S. C., and Palace, V. P.: Chemical-environment interactions affecting the risk of impacts on aquatic organisms: A review with a Canadian perspective - interactions affecting exposure, Environ. Rev., 16, 1-17, 2008.

Curtosi, A., Pelletier, E., Vodopivez, C. L., and MacCormack, W. P.: Polycyclic aromatic hydrocarbons in soil and surface marine sediment near Jubany Station (Antarctica). Role of permafrost as a low-permeability barrier, Sci. Total Environ., 383, 193-204, 2007.

Czuczwa, J., Leuenberger, C., and Giger W.: Seasonal and temporal changes of organic compounds in rain and snow, Atmos. Environ., 22, 907-916, 1988. 
Danon-Schaffer, M. N., Grace, J. R., and Ikonomou, M. G.: PBDEs in waste disposal sites from Northern Canada, Organohalogen Compounds, 70, 365-368, 2008.

Daly, G. L. and Wania, F.: Simulating the influence of snow on the fate of organic compounds, Environ. Sci. Technol., 38, 41764186, 2004.

Daly, G. L. and Wania, F.: Organic contaminants in mountains. Environ. Sci. Technol. 39, 385-398, 2005.

Derksen, C. and Brown, R.: Spring snow cover extent reductions in the 2008-2012 period exceeding climate model projections. Geophys. Res. Lett., 39, L19504, doi:10.1029/2012GL053387, 2012.

Dolinova, J., Ruzicka, R., Kurkova, R., Klánová, J., and Klán, P.: Oxidation of aromatic and aliphatic hydrocarbons by $\mathrm{OH}$ radicals photochemically generated from $\mathrm{H}_{2} \mathrm{O}_{2}$ in ice, Environ. Sci. Technol., 40, 7668-7674, 2006.

Domine, F. and Shepson, P. B.: Air-snow interactions and atmospheric chemistry, Science, 297, 1506-1510, 2002.

Domine, F., Cincinelli, A., Bonnaud, E., Martellini, T., and Picaud, S.: Adsorption of phenanthrene on natural snow, Environ. Sci. Technol., 41, 6033-6038, 2007a.

Domine, F., Taillandier, A.-S., and Simpson, W. R.: A parameterization of the specific surface area of seasonal snow for field use and for models of snow pack evolution, J. Geophys. Res., 112, F2, F02031, doi:10.1029/2006JF000512, 2007b.

Domine, F., Albert, M., Huthwelker, T., Jacobi, H.-W., Kokhanovsky, A. A., Lehning, M., Picard, G., and Simpson, W. R.: Snow physics as relevant to snow photochemistry, Atmos. Chem. Phys., 8, 171-208, doi:10.5194/acp-8-171-2008, 2008.

Domine, F., Gallet, J.-C., Bock, J., and Morin, S.: Structure, specific surface area and thermal conductivity of the snowpack around Barrow, Alaska, J. Geophys. Res., 117, D00R14, doi:10.1029/2011JD016647, 2012.

Dubowski, Y. and Hoffmann, M. R.: Photochemical transformations in ice: Implications for the fate of chemical species, Geophys. Res. Lett., 27, 3321-3324, 2000.

Eichler, A., Schwikowski, M., and Gaggeler, H.: Meltwater induced relocation of chemical species in Alpine firn, Tellus, 53, 192203, 2001

Escher, B. I. and Hermens, J. L. M.: Modes of action in ecotoxicology: their role in body burdens, species sensitivity, QSARs, and mixture effects, Environ. Sci. Technol., 36, 4201-4217, 2002.

Evenset, A., Christensen, G. N., Skotvold, T., Fjeld, E., Schlabach, M., and Wartena, E., Gregor, D.: A comparison of organic contaminants in two high Arctic lake ecosystems, Bjørnøya (Bear Island), Norway, Sci. Total Environ., 318, 125-141, 2004.

Evenset, A., Carroll, J., Christensen, G. N., Kallenborn, R., Gregor, D., and Gabrielsen, G. W.: Seabird guano is an efficient conveyor of persistent organic pollutants (POPs) to arctic lake ecosystems, Environ. Sci. Technol., 41, 1173-1179, 2007a.

Evenset, A., Christensen, G. N., Carroll, J., Zaborska, A., Berger, U., Herzke, D., and Gregor, D.: Historical trends in persistent organic pollutants and metals recorded in sediment from Lake Ellasjøn, Bjørnøya, Norwegian Arctic, Environ. Poll., 146, 196205, 2007b.

Farinotti, D., Huss, M., Bauder, A., and Funk, M.: An estimate of the glacier ice volume in the Swiss Alps, Global Planet. Change, 68, 225-231, 2009.
Finizio, A., DiGuardo, A., and Cartmale, L.: Hazardous air pollutants (HAPs) and their effects on biodiversity: an overview of the atmospheric pathways of persistent organic pollutants (POPs) and suggestions for future studies, Environ. Monit. Assess., 49, 327-336, 1998.

Finizio, A., Villa, S., Raffaele, F., and Vighi, M.: Variation of POP concentrations in fresh-fallen snow and air on an Alpine glacier (Monte Rosa), Ecotoxicol. Environ. Safety, 63, 25-32, 2006.

Foster, K. L., Kimpe, L. E., Brimble, S. K., Liu, H., Mallory, M. L., Smol, J. P., Macdonald, R. W., and Blais, J. M.: Effects of seabird vectors on the fate, partitioning, and signatures of contaminants in a high Arctic ecosystem, Environ. Sci. Technol., 45, 10053 10060, 2011.

Franz, T. P. and Eisenreich, S. J.: Snow scavenging of polychlorinated biphenyls and polycyclic aromatic hydrocarbons in Minnesota, Environ. Sci. Technol., 32, 1771-1778, 1998.

Gabrieli, J., Decet, F., Luchetta, A., Valt, M., Pastore, P., and Barbante, C.: Occurence of PAHs in seasonal snowpack of Eastern Italian Alps, Environ. Pollut., 158, 3130-3137, 2010.

Geisz, H. N., Dickhut, R. M., Chochran, M. A., Fraser, W. R., and Ducklow, H. W.: Melting glaciers: A probable source of DDT to the Antarctic marine ecosystem, Environ. Sci. Technol., 42, 3958-3962, 2008

Gioia, R., Lohmann, R., Dachs, J., Temme, C., Lakaschus, S., Schulz-Bull, D., Hand, I., and Jones, K. C.: Polychlorinated biphenyls in air and water of the North Atlantic and Arctic Ocean, J. Geophy. Res. Atmos., 113, D19302, doi:10.1029/2007JD009750, 2008.

Goss, K.-U., Bronner, G., Harner, T., Hertel, M., and Schmidt, T. C.: The partition behavior of flurortelomer alcohols and olefins, Environ. Sci. Technol., 40, 3572-3577, 2006.

Grannas, A. M., Jones, A. E., Dibb, J., Ammann, M., Anastasio, C., Beine, H. J., Bergin, M., Bottenheim, J., Boxe, C. S., Carver, G., Chen, G., Crawford, J. H., Domine, F., Frey, M. M., Guzman, M. I., Heard, D. E., Helmig, D., Hoffmann, M.R., Honrath, R. E., Huey, L. G., Hutterli, M., Jacobi, H. W., Klán, P., Lefer, B., McConnell, J., Plane, J., Sander, R., Savarino, J., Shepson, P. B., Simpson, W. R., Sodeau, J. R., von Glasow, R., Weller, R., Wolff, E. W., and Zhu, T.: An overview of snow photochemistry: evidence, mechanisms and impacts, Atmos. Chem. Phys., 7, 4329-4373, doi:10.5194/acp-7-4329-2007, 2007a.

Grannas, A. M., Bausch, A. R., and Mahanna, K. M.: Enhanced aqueous photochemical reaction rates after freezing, J. Phys. Chem. A., 111, 11043-11049, 2007b.

Gregor, D. J., Peters, A. J., Teixeira, C., Jones, N., and Spencer, C.: The historical residue trend of PCBs in the Agassiz Ice Cap, Ellesmere Island, Canada, Sci. Total Environ., 160/161, 117126, 1995.

Gregory-Eaves, I., Demers, M. J., Kimpe, L., Krümmel, E. M., Macdonald, R. W., Finney, B. P., and Blais, J. M.: Tracing salmon-derived nutrients and contaminants in freshwater food webs across a pronounced spawner density gradient, Environ. Toxicol. Chem., 26, 1100-1108, 2007

Gouin, T., Mackay, D., Jones, K., Harner, T., and Meijer, S.: Evidence for the "grasshopper" effect and fractionation during longrange atmospheric transport of organic contaminants, Environ. Pollut., 128, 139-148, 2004.

Gouin, T., Wania, F., Ruepert, C., and Castillo, L.: Field testing passive air samplers for current use pesticides in a tropical environ- 
ment, Environ. Sci. Technol., 42, 6624-6630, 2008.

Guglielmo, F., Stemmler, I., and Lammel, G.: The impact of organochlorines cycling in the cryosphere on their global distribution and fate - 1. Sea ice, Environ. Poll., 162, 475-481, 2012.

Guimbaud, C., Grannas, A. M., Shepson, P. B., Fuentes, J. D., Boudries, H., Bottenheim, J. W., Domine, F., Houdier, S., Perrier, S., Biesenthal, T. B., Splawn, B. G.: Snowpack processing of acetaldehyde and acetone in the Arctic atmospheric boundary layer, Atmos. Environ., 36, 2743-2752, 2002.

Gustafsson, O., Andersson, P., Axelman, J., Bucheli, T. D., Koemp, P., McLachlan, M.: Observations of the PCB distribution within and in-between ice, snow, ice-rafted debris, ice-interstitial water, and seawater in the Barents Sea marginal ice zone and the North Pole area, Sci. Total Environ., 342, 261-279, 2005.

Guzman, M. I., Hoffman, M. R., and Colussi, A. J.: Photolysis of pyruvic acid in ice: possible relevance to $\mathrm{CO}$ and $\mathrm{CO}_{2}$ ice core record anomalies, J. Geophys. Res., 112, D10123, doi:10.1029/2006JD007886, 2007.

Hageman, K. J., Hafner, W., Campbell, D. H., Jaffe, D., Landers, D. H., and Simonich, S. L. M.: Variability in pesticide deposition and source contributions to snowpack in western U.S. national parks, Environ. Sci. Technol., 44, 4452-4458, 2010.

Halsall, C. J.: Investigating the occurrence of persistent organic pollutants (POPs) in the arctic: their atmospheric behaviour and interaction with the seasonal snow pack, Environ. Poll., 128, 163175,2004

Hanna, E., Huybrechts, P., Cappelen, J., Steffen, K., Bales, R. C., Burgess, E., McConnell, J. R., Steffensen, J. P., Van den Broeke, M., Wake, L., Bigg, G., Griffiths, M., and Savas, D.: Greenland Ice Sheet surface mass balance 1870 to 2010 based on Twentieth Century Reanalysis, and links with global climate forcing, J. Geophys. Res., 116, D24121, doi:10.1029/2011JD016387, 2011.

Hansen, K. M., Halsall, C. J., and Christensen, J. H.: A dynamic model to study the exchange of gas-phase persistent organic pollutants between air and a seasonal snow pack, Environ. Sci. Technol., 40, 2640-2652, 2006.

Harner, T., Pozo, K., Gouin, T., Macdonald, A.-M., Hung, H., Cainey, J., and Peters, A.: Global pilot study for persistent organic pollutants (POPs) using PUF disk passive air samplers, Environ. Pollut., 144, 445-452, 2006.

Heger, D. and Klán, P.: Interactions of organic molecules at grain boundaries in ice: A solvatochromic analysis, J. Photochem. Photobiol. A-Chem., 187, 275-284, 2007.

Heger, D., Jirkovsky, J., and Klán, P.: Aggregation of methylene blue in frozen aqueous solutions studied by absorption spectroscopy, J. Phys. Chem. A, 109, 6702-6709, 2005.

Heger, D., Klánová, J., and Klán, P.: Enhanced protonation of cresol red in acidic aqueous solutions caused by freezing, J. Phys. Chem. B, 110, 1277-1287, 2006.

Heger, D., Nachtigallova, D., Surman, F., Krausko, J., Magyarova, B., Brumovsky, M., Rubes, M., Gladich, I., and Klán, P.: SelfOrganization of 1-Methylnaphthalene on the Surface of Artificial Snow Grains: A Combined Experimental-Computational Approach, J. Phys. Chem. A, 115, 11412-11422, 2011.

Herbert, B. M. J., Halsall, C. J., Villa, S., Fitzpatrick, L., Jones, K. C., Lee, R. G. M., and Kallenborn, R.: Polychlorinated naphthalenes in air and snow in the Norwegian Arctic: a local source or an Eastern Arctic phenomenon? Sci. Total Environ., 342, 145160, 2005a.
Herbert, B. M. J., Halsall, C. J., Villa, S., Jones, K. C., and Kallenborn, R.: Rapid changes in PCB and OC pesticide concentrations in Arctic snow, Environ. Sci. Technol., 39, 2998-3005, 2005 b.

Herbert, B. M. J., Villa, S., and Halsall, C.: Chemical interaction with snow: Understanding the behaviour and fate of semi-volatile organic compounds in snow, Ecotox. Environ. Safety, 63, 3-16, 2006.

Hermanson, M. H., Isaksson, E., Texixeira, C., Muir, D. C. G., Compher, K. M., Li, Y.-F., Igargashi, M., and Kamiyama, K.: CurrentUse and Legacy Pesticide History in the Austfonna Ice Cap, Svalbard, Norway, Environ. Sci. Technol., 39, 8163-8169, 2005.

Hermanson, M. H., Isaksson, E., Forsstrom, S., Teixeria, C., Muir, D. C. G., Pohjola, V. A., and Van de Wal, R. S. V.: Deposition history of brominated flame retardant compounds in an ice core from Holtedahlfonna, Svalbard, Norway, Environ. Sci. Technol., 44, 7405-7410, 2010.

Hoff, J. T., Wania, F., Mackay, D., and Gillham, R.: Sorption of nonpolar organic vapors by ice and snow, Environ. Sci. Technol., 29, 1982-1989, 1995.

Hoffmann, L., Stemmler, I., and Lammel, G.: The impact of organochlorines cycling in the cryosphere on global distributions and fate -2 . Land ice and temporary snow cover, Environ. Poll., 162, 482-488, 2012.

Hoyau, V., Laffrezo, J. L., Garrigues, P. H., Clain, M. P., and Masclet, P.: Deposition of aerosols in polar regions - Contamination of the ice sheet by polycyclic aromatic hydrocarbons, Polycycl. Arom. Comp., 8, 35-44, 1996.

Hung, H., Kallenborn, R., Breivik, K., Su, Y., Brorstrøm-Lunden, E., Olafsdottir, K, Thorlacius, J. M., Leppanen, S., Bossi, R., Skov, H., Manø, S., Stern, G., Sverko, E., and Fellin, P.: Atmospheric monitoring of organic pollutants in the Arctic under the Arctic Monitoring and Assessment Programme (AMAP): 1993 2006, Sci. Total Environ., 408, 2854-2873, 2010.

IPCC: Climate Change 2007: Synthesis Report - Contribution of Working Groups I, II and III to the Fourth Assessment Report of the Intergovernmental Panel on Climate Change, p. 104. 2007.

Isaksson, E., Hermanson, M. H., Hicks, S., Igarashi, M., Kamiyama, K., Moore, J., Motoyama, H., Muir, D. C. G., Pohjola, V., Vaikmaë, R., van de Wal, R. S. W., and Watanabe, O.: Ice cores from Svalbard - useful archives of past climate and pollution history, Phys. Chem. Earth, 28, 1217-1228, 2003.

Jacobi, H. W., Annor, T., and Quansah, E.: Investigation of the photochemical decomposition of nitrate, hydrogen peroxide, and formaldehyde in artificial snow, J. Photochem. Photobiol. AChem, 179, 330-338, 2006.

Jaffrezo, J. L., Clain, M. P., and Masclet, P.: Polycyclic aromatichydrocarbons in the polar ice of greenland - geochemical use of these atmospheric tracers, Atmos. Environ., 28, 1139-1145, 1994.

Jantunen, L. M. and Bidleman T. F.: Air-water gas exchange of $\mathrm{HCHs}$ and the enantiomers of alpha- $\mathrm{HCH}$ in arctic regions, J. Geophys. Res., 101, 28837-28846, 1996.

Jantunen, L. M., Helm, P. A., Kylin, H., and Bidleman, T. F.: HCHs in the Canadian Archipelago. 2. Air-water gas exchange of alphaand gamma-HCHs, Environ. Sci. Technol., 42, 465-470, 2008.

Johannessen, M. and Henriksen, A.: Chemistry of snow meltwater: Changes in concentration during melting, Water Resour. Res., 14, 615-619, 1978. 
Kahan, T. F. and Donaldson, D. J.: Photolysis of polycyclic aromatic hydrocarbons on water and ice surfaces, J. Phys. Chem. A, 111, 1277-1285, 2007.

Kahan, T. F. and Donaldson, D. J.: Benzene photolysis on ice: Implications for the fate of organic contaminants in the winter, Environ. Sci. Technol., 44, 3819-3824, 2010.

Kahan, T. F., Zhao, R., Jumaa, K. B., and Donaldson, D. J.: Anthracene photolysis in aqueous solution and ice: Photon flux dependence and comparison of kinetics in bulk ice and at the air-ice interface, Environ. Sci. Technol., 44, 1302-1306, 2010.

Kallenborn, R., Breivik, K., Eckhardt, S., Lunder, C. R., Manø, S., Schlabach, M., and Stoh A.: Long-term monitoring of persistent organic pollutants (POPs) at the Norwegian Troll station in Dronning Maud Land, Antarctica, Atmos. Chem. Phys. Discuss., 13, 6219-6246, doi:10.5194/acpd-13-6219-2013, 2013.

Kammerer, P. A. and Lee, G. F.: Freeze concentration of organic compounds in dilute aqueous solution, Environ. Sci. Technol., 3, 276-278, 1969.

Kang, J. H., Choi, S. D., Rak, H., Baek, S. Y., Hong, S., and Chang, T. S.: Atmospheric deposition of persistent organic pollutants to the East Rongbuk Glacier in the Himalayas, Sci. Total. Environ. 408, 57-63, 2009.

Kinloch, D., Kuhnlein, H., and Muir, D. C. G.: Inuit foods and diet: a preliminary assessment of benefits and risks, Sci. Total Environ., 122, 247-278, 1992.

Klán, P. and Holoubek, I.: Ice (photo)chemistry. Ice as a medium for long-term (photo)chemical transformations - environmental implications, Chemosphere, 46, 1201-1210, 2002.

Klán, P., Ansorgova, A., Del Favero, D., and Holoubek, I.: Photochemistry of chlorobenzene in ice, Tetrahedron Lett., 41, 77857789, 2000a.

Klán, P., Janosek, J., and Kriz, Z.: Photochemistry of valerophenone in solid solutions, J. Photochem. Photobiol. A-Chem., 134, $37-$ 44, 2000b.

Klán, P., Del Favero, D., Ansorgova, A., Klánová, J., and Holoubek, I.: Photodegradation of halobenzenes in water ice, Environ. Sci. Pollut. Res., 8, 195-200, 2001.

Klán, P., Klánová, J., Holoubek, I., and Cupr, P.: Photochemical activity of organic compounds in ice induced by sunlight irradiation: The Svalbard project, Geophys. Res. Lett., 30, 1313, doi:10.1029/2002GL016385, 2003.

Klánová, J., Klán, P., Heger, D., and Holoubek, I.: Comparison of the effects of $\mathrm{UV}, \mathrm{H}_{2} \mathrm{O}_{2} / \mathrm{UV}$ and gamma- irradiation processes on frozen and liquid water solutions of monochlorophenols, Photochem. Photobiol. Sci., 2, 1023-1031, 2003a.

Klánová, J., Klán, P., Nosek, J., and Holoubek, I.: Environmental ice photochemistry: monochlorophenols, Environ. Sci. Technol., 37, 1568-1574, 2003b.

Krümmel, E., Macdonald, R. W., Kimpe, L. E., Gregory-Eaves, I., Demers, D. J., Smol, J. P., Finney, B., and Blais, J. M.: Anadromous PCB transport via Salmon migration, Nature, 425, 255256, 2003.

Krusic, P. J., Marchione, A. A., Davidson, F., Kaiser, M. A., ChienPing, C. K., Richardson, R. E., Botoelho, M., Waterland, R. L., and Buck, R. C.: Vapor Pressure and Intermolecular Hydrogen Bonding in Fluorotelemer Alcohols, J. Phys. Chem. A, 109, 6232-6241, 2005.

Kurková, R., Ray, D., Nachtigallova, D., and Klán, P.: Chemistry of small organic molecules on snow grains: The applicability of artificial snow for environmental studies, Environ. Sci. Technol., 45, 3430-3436, 2011.

Kwok, R., Cunningham, G. F., Wensnahan, M., Rigor, I., Zwally, J. J. and Yi, D.: Thinning and volume loss of the Arctic Ocean sea ice cover: 2003-2008, J. Geophys. Res., 114, C07005, doi:10.1029/2009JC005312, 2009.

Lafrenière, M. J., Blais, J. M., Sharp, M. J., and Schindler, D. W.: Organochlorine pesticide and polychlorinated biphenyl concentrations in snow, snowmelt, and runoff at Bow Lake, Alberta, Environ. Sci. Technol., 40, 4909-4915, 2006.

Lange, M. A. and Pfirman, S. L.: Arctic sea ice contamination: major characteristics and consequences, edited by: Lepparanta, M., in: Physics of Ice-covered Seas, vol 2. Helsinki University Printing House, Helsinki, 651-681, 1998.

Lange, M. A., Schlosser, P., Ackley, S. F., Wadhams, P., and Piekmann, G. S.: ${ }^{18} \mathrm{O}$ concentrations in sea ice of the Weddell Sea, Antarctica, J. Glaciol., 36, 315-323, 1990.

Legagneux L., Carbanes, A., and Domine F.: Measurement of the specific area of 176 snow samples using methane adsorption at 77K, J. Geophys. Res., 107, 4335, doi:10.1029/2001JD001016, 2002.

Lei, Y. D. and Wania, F.: Is rain or snow a more efficient scavenger of organic chemicals? Atmos. Environ., 38, 3557-3571, 2004.

Lei, Y. D., Wania, F., Mathers, D., and Mabury, S. A.: Determination of vapor pressures, octanol-air, and water-air partition coefficients for polyfluorinated sulfonamide, sulfonamidoethanols, and telomer alcohols, J. Chem. Eng. Data, 49, 1031-1022, 2004. Li, Y.-F., Macdonald, R. W., Jantunen, L. M. M., Harner, T., Bidleman, T. F., and Strachan, W. M. J.: The transport of betahexachlorocyclohexane to the western Arctic Ocean: a contrast to alpha-HCH, Sci. Total Environ., 291, 229-246, 2002.

Li, N., Wania, F., Lei, Y. D., and Daly, G. L.: A comprehensive and critical compilation, evaluation, and selection of physicalchemical property data for selected polychlorinated biphenyls, J. Phys. Chem. Ref. Data, 32, 1545-1590, 2003.

Li, Y.-F., Macdonald, R. W., Ma, J. M., Hung, H., and Venkatesh, S.: Historical a-HCH budget in the Arctic Ocean: The Arctic mass balance box model (AMBBM), Sci. Total Environ., 324, 115139, 2004.

Li, Y.-F. and Macdonald, R. W.: Sources and pathways of selected organochlorine pesticides to the Arctic and the effect of pathway divergence on $\mathrm{HCH}$ trends in biota: a review, Sci. Total Environ., 342, 87-106, 2005.

Lindsay, R. W., Zhang, J., Schweiger, A., Steele, M., and Stern, H.: Arctic Sea Ice Retreat in 2007 Follows Thinning Trend, J. Climate, 22, 165-176, 2009.

Literak, J., Klán, P., Heger, D., and Loupy, A.: Photochemistry of alkyl aryl ketones on alumina, silica-gel and water ice surfaces, J. Photochem. Photobiol. A-Chem., 154, 155-159, 2003.

Lockhart, W. L., Wagemann, R., Tracey, B., Sutherland, D., and Thomas, D. J.: Presence and implications of chemical contaminants in the freshwaters of the Canadian Arctic, Sci. Total Environ., 122, 165-243, 1992.

Loewe, H., Spiegel, J. K., and Schneebeli, M.: Interfacial and structural relaxations of snow under isothermal conditions, J. Glaciol., 57, 499-510, 2011.

Lohmann, R., Gioia, R., Jones, K. C., Nizzetto, L., Temme, C., Xie, Z., Schulz-Bull, D., Hand, I., Morgan, E., and Jantunen, L.: Organochlorine pesticides and PAHs in the surface water and at- 
mosphere of the north Atlantic and Arctic Ocean, Environ. Sci. Technol., 43, 5633-5639, 2009.

Ma, J., Hung, H., Tian, C., and Kallenborn, R.: Revolatilization of persistent organic pollutants in the Arctic induced by climate change, Nature Clim. Change, 1, 256-260, 2011.

Macdonald, R. W., Barrie, L. A., Bidleman, T. F., Diamond, M. L., Gregor, D. J., Semkin, R. G., Strachan, W. M. J., Li, Y. F., Wania, F., Alaee, M., Alexeeva, L. B., Bailey, S. M. B. R., Bewers, J. M., Gobeil, C., Halsall, C. J., Harner, T., Hoff, J. T., Jantunen, L. M. M., Lockhart, W. L., Mackay, D., Muir, D. C. G., Pudykiewicz, J., Reimer, K. J., Smith, J. N., Stern, G. A., Schroeder, W. H., Wagemann, R., and Yunker, M. B.: Contaminants in the Canadian Arctic: 5 years of progress in understanding sources, occurrence and pathways, Sci. Total Environ., 254, 93-234, 2000.

Macdonald, R. W., Mackay, D., Li, Y.-F., and Hickie, B.: How will global climate change affect risks from long-range transport of persistent organic pollutants?, Human Ecol. Risk Assess., 9, 643-660, 2003a.

Macdonald, R. W., Harner, T., Fyfe, J., Loeng, H., and Weingartner, T.: The influence of global change on contaminant pathways to, within and from the Arctic, Arctic Monitoring and Assessment Program (AMAP), Oslo, Norway, 65 pp., 2003 b.

Macdonald, R. W., Harner, T., and Fyfe, J.: Recent climate change in the Arctic and its impact on contaminant pathways and interpretation of temporal trend data, Sci. Total Environ., 342, 5-86, 2005.

Mackay, D., Shiu, W. Y., Ma, K.-C., and Lee, S. C.: Handbook of physical-chemical properties and environmental fate for organic chemicals, CRC Press, 4216 pp., 2006.

Mann, E., Meyer, T., Mitchell, C. P. J., and Wania, F.: Mercury fate in ageing and melting snow: Development and testing of a controlled laboratory system, J. Environ. Monit., 13, 2695-2702, 2011.

Mast, A. M., Foreman, W. T., and Skaates, S. V.: Current-use pesticides and organochlorine compounds in precipitation and lake sediment from two high-elevation national parks in the Western United States, Arch. Environ. Contam. Toxicol., 52, 294-305, 2007.

Matykiewiczová, N., Klánová, J., and Klán, P.: Photochemical degradation of PCBs in snow, Environ. Sci. Technol., 41, 83088314, 2007a.

Matykiewiczová, N., Kurkova, R., Klánová, J., and Klán, P.: Photochemically induced nitration and hydroxylation of organic aromatic compounds in the presence of nitrate or nitrite in ice, J. Photochem. Photobiol. A-Chem., 187, 24-32, $2007 \mathrm{~b}$.

Mayewski, P. A., Meredith, M. Summerhayes, C., Turner, J., Aoki, S., Barrett, P. Bertler, N. A. N., Bracegirdle, T., Bromwich, D., Campbell, H., Casassa, G., Garabato, A. N., Lyons, W. B., Maasch, K. A., Worby, A., and Xiao, C.: State of the Antarctic and Southern Ocean Climate System (SASOCS), Rev. Geophys., 47, RG1003, doi:10.1029/2007RG000231, 2009.

McConnell, J. R.: Role and Importance of Cryospheric Processes in Climate System, Encycl. Hydrol. Sci., doi:10.1002/0470848944.hsa208, 2006.

McConnell, L. L., LeNoir, J. S., Datta, S., and Seiber, J. N.: Wet deposition of current-use pesticides in the Sierra Nevada Mountain Range California, USA, Environ. Toxicol. Chem., 17, 19081916, 1998.
McNeill, V. F., Grannas, A. M., Abbatt, J. P. D., Ammann, M., Ariya, P., Bartels-Rausch, T., Domine, F., Donaldson, D. J., Guzman, M. I., Heger, D., Kahan, T. F., Klán, P., Masclin, S., Toubin, C., and Voisin, D.: Organics in environmental ices: sources, chemistry, and impacts, Atmos. Chem. Phys., 12, 9653-9678, doi:10.5194/acp-12-9653-2012, 2012.

Melnikov, S., Carrol, J., Goshkov, A., Vlasov, S., and Dahle, S.: Snow and ice concentrations of selected persistent pollutants in the Ob-Yenisey River watershed, Sci. Total Environ., 306, 27-37, 2003.

Meier, M. F., Dyurgerov, M. B., Rick, U. K., O’Neel, S., Pfeffer, W. T., Anderson, R. S., Anderson, S. P., and Glazovsky, A. F.: Glaciers dominate eustatic sea-level rise in the 21 st century, Science, 317, 1064-1067, 2007.

Meyer, T. and Wania, F.: Organic contaminant amplification during snowmelt, Water Res., 42, 1847-1865, 2008.

Meyer, T. and Wania, F.: Modeling the elution of organic chemicals from a melting homogeneous snow pack, Water Res., 45, 3627 3637, 2011a.

Meyer, T. and Wania, F.: Atmosphere-snow exchange, in: Handbook of Chemical Mass Transport in the Environment, edited by: Thibodeaux, L. J. and Mackay, D., Publisher CRC Press/Taylor \& Francis, 513-530, 2011b.

Meyer, T., Lei, Y. D., and Wania, F.: Measuring the release of organic contaminants from melting snow under controlled conditions, Environ. Sci. Technol., 40, 3320-3326, 2006.

Meyer, T., Lei, Y. D., Muradi, I., and Wania, F.: Organic contaminant release from melting snow: I. Influence of chemical partitioning, Environ. Sci. Technol., 43, 657-662, 2009a.

Meyer, T., Lei, Y. D., Muradi, I., and Wania, F.: Organic contaminant release from melting snow: II. Influence of snow pack and melt characteristics, Environ. Sci. Technol., 43, 663-668, 2009b.

Meyer, T., Lei, Y. D., and Wania, F.: Transport of polycyclic aromatic hydrocarbons and pesticides during snowmelt within an urban watershed, Water Res., 45, 1147-1156, 2011 a.

Meyer, T., De Silva, A. O., Spencer, C., and Wania, F.: The fate of perfluorinated carboxylates and sulfonates during snowmelt within an urban watershed, Environ. Sci. Technol., 45, 81138119, $2011 b$.

Meyer, T., Muir, D. C. G., Teixeira, C., Wang, X., Young, T., and Wania, F.: Deposition of brominated flame retardants to the Devon Ice Cap, Nunavut, Canada, Environ. Sci. Technol., 46, 826833, 2012.

Michelutti, N., Keatley, B. E., Brimble, S., Blais, J. M., Liu, H., Douglas, M. S. V., Mallory, M. L., Macdonald, R. W., and Smol, J. P.: Seabird-driven shifts in Arctic pond ecosystems, Proc. Roy. Soc. B: Biol. Sci., 276, 591-596, 2008.

Michelutti, N., Liu, H., Smol, J. P., Kimpe, L. E., Keatley, B. E., Mallory, M. L., Macdonald, R. W., Douglas, M. S. V., and Blais, J. M.: Accelerated delivery of polychlorinated biphenyls (PCBs) in recent sediments near a large seabird colony in Arctic Canada, Environ. Poll., 157, 2769-2775, 2009.

Muir, D. C. G., Wagemann, R., Hargrave, B. R., Thomas, D. J., Peakall, D. B., and Norstrom, R. J.: Arctic marine ecosystem contamination, Sci. Total Environ., 122, 75-134, 1992.

Nakazawa, T., Ishizawa, M., Higuchi, K., and Trivett, N. B. A.: Two curve fitting methods applied to $\mathrm{CO} 2$ flask data, Environmetrics, 8, 197-218, 1997. 
Nie, Y., Liu, X., Sun, L., and Emslie, S. D.: Effect of penguin and seal excrement on mercury distribution in sediments from the Ross Sea region, East Antarctica, Sci. Total Environ., 433, 132140, 2012.

Nielsen, J. L., Ruggerone, G. T., and Zimmerman, C. E.: Adaptive strategies and life history characteristics in a warming climate: Salmon in the Arctic?, Environ. Biol. Fish., doi:10.1007/s10641012-0082-6, 2012.

Nilsen, F., Cottier, F., Skogseth, R., and Mattson, S.: Fjord-shelf exchanges controlled by ice and brine production: The interannual variation of Atlantic Water in Isfjorden, Svalbard, Cont. Shelf Res. 28, 1838-1853, 2008.

NOAA National Climatic Data Center, State of the Climate: Global Snow \& Ice for September 2012, published online October 2012, retrieved on 6 March 2013 from http://www.ncdc.noaa.gov/sotc/ global-snow/2012/9, 2012.

NRC: Critical infrastructure for ocean research and societal needs in 2030, National Research Council of the National Academies, National Academies Press, Washington DC, 88 pp., 2011.

Oehme, M.: Further evidence for long-range air transport of polychlorinated aromates and pesticides: North America and Eurasia to the Arctic, Ambio, 20, 293-297, 1991.

Oehme, M. and Mano, S.: The long-range transport of organic pollutants to the Arctic, Fresenius' J. Anal. Chem., 319, 141-146, 1983.

Olsen, M. S., Callaghan, T. V., Reist, J. D., Reiersen, L. O., DahlJensen, D., Granskog, M. A., Goodison, B., Hovelsrud, G. K., Johansson, M., Kallenborn, R., Key, J., Klepikov, A., Meier, W., Overland, J. E., Prowse, T. D., Sharp, M., Vincent, W. F., and Walsh, J. E.: The changing Arctic cryosphere and likely consequences: An overview, Ambio 40, 111-118, 2011.

Parrinello, T., Mardle, N., Ortega, B., Bouzinac, C., Badessi, S., Frommknecht, B., Davidson, M., Cullen, R., and Wingham, D.: CryoSat: ESA's ice explorer mission. One year in operations: status and achievements, Geophys. Res. Abstr., 14, EGU2012-3478, EGU General Assembly, 2012.

Pavlov,V.: Modelling of long-range transport of contaminants from potential sources in the Arctic Ocean by water and sea ice, edited by: Orbaek, J. B.,Tombre, T., Kallenborn, R., Hegseth, E., Falk-Petersen, S., and Hoel A. H., in: Arctic-alpine Ecosystems and People in a Changing Environment, Springer Verlag, Berlin, 329-350, 2007.

Peel, D. A.: Organochlorine residues in Antarctic snow, Nature, 254, 324-325, 1975.

Perovich, D. K.: The Changing Arctic Sea Ice Cover, Oceanography, 24, 162-173, 2011.

Peterle, T. J.: DDT in Antarctic Snow, Nature, 224, 620, 1969.

Pfirman, S. L., Eicken, H., Bauch, D., and Weeks, W. F. The potential transport of pollutants by Arctic sea ice, Sci. Total Environ., 159, 129-146, 1995.

Plassmann, M., Meyer, T., Lei, Y. D., Wania, F., McLachlan, M. S., and Berger, U.: Theoretical and experimental simulation of the fate of semifluorinated n-alkanes during snow melt, Environ. Sci. Technol., 44, 6692-6697, 2010.

Plassmann, M., Meyer, T., Lei, Y. D., Wania, F., McLachlan, M. S., and Berger, U.: Laboratory study on the fate of perfluorinated carboxylates and sulfonates during snow melt, Environ. Sci. Technol., 45, 6872-6878, 2011.
Post, E., Forchhammer, M. C., Bret-Harte, M. S., Callaghan, T. V., Christensen, T. R., Elberling, B., Fox, A. D., Gilg, O., Hik, D. S., Hoye, T. T., Ims, R. A., Jeppesen, E., Klein, D .R., Madsen, J., McGuire, A. D., Rysgaard, S., Schindler, D. E., Stirling, I., Tamstorf, M. P., Tyler, N. J. C., van der Wal, R., Wleker, J., Wookey, P. A., Schmidt, N. M., and Aastrup, P.: Ecological dynamics across the Arctic associated with recent climate change, Science, 325, 1355-1358, 2009.

Pruppacher, H. R. and Klett, J. D.: Microphysics of clouds and precipitation, Reidel Pub. Co., Dordrecht, the Netherlands, 976 pp., 1978.

Pućko, M., Stern, G. A., Barber, D. G., Macdonald, R. W., and Rosenberg, B.: The International Polar Year (IPY) Circumpolar Flaw Lead (CFL) System Study: the importance of brine processes for $\alpha$ - and $\gamma$-hexachlorocyclohexane $(\mathrm{HCH})$ accumulation/rejection in the sea ice, Atmos. Ocean., 48, 244-262, 2010a.

Pućko, M., Stern, G. A., Macdonald, R. W., and Barber, D. G.: $\alpha$ and $\gamma$-hexachlorocyclohexane $(\mathrm{HCH})$ measurements in the brine fraction of sea ice in the Canadian High Arctic using a sump-hole technique, Environ. Sci. Technol., 44, 9258-9264, 2010b.

Pućko, M., Stern, G. A., Macdonald, R. W., Barber, D. G., and Rosenberg, B.: The influence of the atmosphere-snow-ice-ocean interactions on the levels of hexachlorocyclohexanes (HCHs) in the Arctic cryosphere, J. Geophys. Res., 116, C02035, doi:10.1029/2010JC00661, 2011a.

Pućko, M., Stern, G.A., Macdonald, R. W., Barber, D. G., Rosenberg, B., and Walkusz, W.: When will $\alpha-\mathrm{HCH}$ disappear from the Arctic Ocean?, J. Mar. Syst., doi:10.1016/j.jmarsys.2011.09.007, $2011 b$.

Ram, K. and Anastasio, C.: Photochemistry of phenanthrene, pyrene, and fluoranthene in ice and snow, Atmos. Environ., 43, 2252-2259, 2009.

Ray, D., Kurkova, R., Hovorkova, I., and Klán, P.: Determination of the Specific Surface Area of Snow Using Ozonation of 1,1-Diphenylethylene, Environ. Sci. Technol., 45, 10061-10067, 2011.

Ray, D., Malongwe, J. K., and Klán, P.: Rate Acceleration of the Heterogeneous Reaction of Ozone with a Model Alkene at the Air-Ice Interface at Low Temperatures, Environ. Sci. Technol., doi:10.1021/es304812t, 2013.

Risebrough, R. W., Walker II, W., Schmidt, T. T., De Lappe, B. W., and Connors, C. W.: Transfer of chlorinated biphenyls to Antarctica, Nature, 264, 738-739, 1976.

Risebrough, R. W., De Lappe, B. W., and Younghans-Haug, C.: PCB and PCT contamination in Winter Quarters Bay, Antarctica, Marine Poll. Bull., 21, 523-529, 1990.

Roosens, L., Van Den Brink, N., Riddle, M., Blust, R., Neels, H., and Covaci, A.: Penguin colonies as secondary sources of contamination with persistent organic pollutants, J. Environ. Monit., 9, 822-825, 2007.

Roth, C. M., Goss, K.-U., and Schwarzenbach, R. P.: Sorption of diverse organic vapors to snow, Environ. Sci. Technol., 38, 40784084, 2004.

Rowland, G. A., Bausch, A. R., and Grannas, A. M.: Photochemical processing of aldrin and dieldrin in frozen aqueous solutions under Arctic field conditions, Environ. Poll., 159, 1076-1084, 2011.

Ruggirello, R. M., Hermanson, M. H., Isaksson, E., Teixeira, C., Forsström, S., Muir, D. C. G., Pohjola, V., van de Wal, R., and 
Meijer, H. A. J.: Current use and legacy pesticide deposition to ice caps on Svalbard, Norway, J. Geophys. Res., 115, D18308, doi:10.1029/2010JD014005, 2010.

Ruzicka, R., Barakova, L., and Klán, P.: Photodecarbonylation of dibenzyl ketones and trapping of radical intermediates by copper(II) chloride in frozen aqueous solutions, J. Phys. Chem. B, 109, 9346-9353, 2005.

Schenker, U., MacLeod, M., Scheringer, M., and Hungerbuhler, K.: Improving data quality for environmental fate models: a leastsquares adjustment procedure for harmonizing physicochemical properties of organic compounds, Environ. Sci. Technol., 39, 8434-8441, 2005.

Scheringer, M.: Long-range transport of organic chemicals in the environment. Environ. Toxicol. Chem., 28, 677-690, 2009.

Schmid, P., Bogdal, C., Bluthgen, N., Anselmetti, F. S., Zwyssig, A., and Hungerbuehler, K.: The Missing Piece: Sediment Records in Remote Mountain Lakes Confirm Glaciers Being Secondary Sources of Persistent Organic Pollutants, Environ. Sci. Technol., 45, 203-208, 2011.

Schöndorf, T. and Herrmann, R.: Transport and chemodynamics of organic micropollutants and ions during snowmelt, Nordic Hydrol., 18, 259-278, 1987.

Serreze, M. C., Barrett, A. P., Slater, A. G., Woodgate, R. A., Aagaard, K., Lammers, R. B., Steele, M., Moritz, R., Meredith, M., and Lee, C. M.: The large-scale freshwater cycle of the Arctic, J. Geophys. Res. 111, C11010, doi:10.1029/2005JC003424, 2006.

Serreze, M.C., Holland, M.M., Stroeve, J.: Perspectives on the Arctic's shrinking sea ice cover, Science, 315, 1533-1536, 2007.

Sharp, M., Burgess, D., Cogley, J. G., Ecclestone, M., Labine, C., and Wolken, G. J.: Extreme melt on Canada's Arctic ice caps in the 21st century, Geophys. Res. Lett., 38, L11501, doi:10.1029/2011GL047381, 2011.

Shen, L. and Wania, F.: Compilation, evaluation, and selection of physical-chemical property data for organochlorine pesticides, J. Chem. Eng. Data, 50, 742-768, 2005.

Slaymaker, O. and Kelly, E.: The cryosphere and global environmental change. Environmental systems and global change series. Blackwell Publishing, ISBN:978-1-4051-2976-3, p. 256, 2007.

Slubowska-Wodengen, M., Rasmussen, T. L., Koc, N., KlitgaardKristensen, D., Nilsen, F., and Solheim, A.: Advection of Atlantic Water to the western and northern Svalbard shelf since 17,500 cal yr BP, Quat. Sci. Rev., 26, 463-478, 2007.

Sobek, A., Reigstad, M., and Gustaffson, O.: Partitioning of polychlorinated biphenyls between arctic seawater and sizefractionated zooplankton, Environ. Toxicol. Chem., 25, 17201728, 2006.

Starokozhev, E., Fries, E., Cycura, A., and Püttman, W.: Distribution of VOCs between air and snow at the Jungfraujoch high alpine research station, Switzerland, during CLACE 5 (winter 2006), Atmos. Chem. Phys., 9, 3197-3207, doi:10.5194/acp-93197-2009, 2009.

Steele, M., Ermold, W., and Zhang, J.: Arctic Ocean surface warming trends over the past 100 years, Geophys. Res. Lett., 35, L02614, doi:10.1029/2007GL031651, 2008.

Stock, N. L., Ellis, D. A., Deleebeeck, L., Muir, D. C. G., and Mabury, S. A.: Vapor Pressures of the Fluorinated Telomer Alcohols -Limitations of Estimation Methods, Environ. Sci. Technol., $38,1693-1699,2004$
Stocker, J., Scheringer, M., Wegmann, F., and Hungerbühler, K.: Modeling the effect of snow and ice on the global environmental fate and long-range transport potential of semivolatile organic compounds, Environ. Sci. Technol., 41, 6192-6198, 2007.

Stroeve, J., Holland, M. M., Meier, W., Scambos, T., and Serreze, M.: Arctic sea ice decline: Faster than forecast, Geophys. Res. Lett., 34, L09501, doi:10.1029/2007GL029703, 2007.

Stroeve, J., Kattsov, V., Barrett, A., Serreze, M., Pavlova, T., Holland, M., and Meier, W. N.: Trends in Arctic sea ice extent from CMIP5, CMIP3 and observations, Geophys. Res. Lett., 39, L16502, doi:10.1029/2012GL052676, 2012.

Sturm, M., Holmgren, J., and Liston, G. E.: A seasonal snow cover classification system for local to global applications, J. Climate, 8, 1261-1283, 1995.

Su, Y., Hung, H., Blanchard, P., Patton, G. W., Kallenborn, R., Konoplev, A., Fellin, P., Li, H., Geen, C., Stern, G., Rosenberg, B., and Barrie L. A.: Spatial and seasonal variations of hexachlorocyclohexanes (HCHs) and hexachlorobenzene (HCB) in the Arctic atmosphere, Environ. Sci. Technol., 40, 6601-6607, 2006.

Su, Y., Hung, H., Blanchard, P., Patton, G. W., Kallenborn, R., Konoplev, A., Fellin, P., Li, H., Green, C., Stern, G., Rosenberg, B., and Barrie, L. A.: A circumpolar perspective of atmospheric organochlorine pesticides (OCPs): Results from six Arctic monitoring stations in 2000-2003, Atmos. Environ., 42, 4682-4698, 2008 .

Sunderland, E. M., Krabbenhoft, D. P., Moreau, J. W., Strode, S. A., and Landing, W. M.: Mercury sources, distribution, and bioavailability in the North Pacific Ocean: Insights from data and models, Global Biogeochem. Cy., 23, GB2010, doi:10.1029/2008GB003425, 2008.

Taillandier, A.-S., Domine, F., Simpson, W. R., Sturm, M., Douglas, T. A., and Severin, K.: Evolution of the snow area index of the subarctic snow pack in Central Alaska over a whole season. Consequences for the air to snow transfer of pollutants, Environ. Sci. Technol., 40, 7521-7527, 2006.

Tanabe, S., Hidaka, H., and Tatsukawa, R.: PCBs and chlorinated hydrocarbon pesticides in Antarctic atmosphere and hydrosphere, Chemosphere, 12, 277-288, 1983.

Thies, H., Kickus, U., Mair, V., Tessadri, R., Tait, D., Thaler, B., and Psenner, R.: Unexpected response of high alpine lake waters to climate warming, Environ. Sci. Technol., 41, 7424-7429, 2007.

Thomas, D. J., Tracey, B., Marshall, H., and Norstrom, R. J.: Arctic terrestrial ecosystem contamination, Sci. Tot. Environ., 122, 135-164, 1992.

Tsiouris, S., Vincent, C. E., Davies, T. D., and Brimblecombe, P.: The elution of ions through field and laboratory snow packs, Ann. Glaciol., 7, 196-201, 1985.

UNECE: Protocol to the 1979 convention on long-range transboundary air pollution on persistent organic pollutants, United Nations, Treaty Series, 2230, p. 79. Document of the Economic and Social Council EB.AIR/1998/2, 1998.

UNECE: Hemispheric transport of air pollution 2010, part C: Persistent organic pollutants, United Nations, Air Pollution Studies No. 19, Geneva, ECE/EB.AIR/10, 2010.

UNEP: Global monitoring report under the global monitoring plan for effectiveness evaluation. UNEP/POPS/COP.4/33, Secretariat of the Stockholm Convention Geneva, 20 pp., 2009. 
UNEP: Success Stories, Stockholm Convention 2001-2011, Secretariat of the Stockholm Convention Geneva, 169 pp., 2012.

UNEP/AMAP: Climate change and POPs: predicting the impacts, Report of the UNEP/AMAP expert group. Secretariat of the Stockholm Convention Geneva, 62 pp., 2011.

Usenko, S., Landers, D. H., Appleby, P. G., and Simonich, S. L.: Current and historical deposition of PBDEs, pesticides, PCBs, and PAHs to Rocky Mountain National Park, Environ. Sci. Technol., 41, 7235-7241, 2007.

Vighi, M.: The role of high mountains in the global transport of persistent organic pollutants, Ecotox. Environ. Safety, 63, 108$112,2006$.

Villa, S., Negrelli, C., Maggi, V., Finzio, A., and Vighi, M.: Analysis of a firn core for assessing POP seasonal accumulation on an Alpine glacier, Ecotoxicol. Environ. Safety, 63, 17-24, 2006.

Wang, R., Tao, S., Wang, B., Yang, Y., Lang, C., Zhang, Y., Hu, J., Ma, J., and Hung, H.: Sources and Pathways of Polycyclic Aromatic Hydrocarbons Transported to Alert, the Canadian High Arctic, Environ. Sci. Technol., 44, 1017-1022, 2010.

Wang, X., Xu, B., Kang, S., Cong, Z., and Yao, T.: The historical residue trends of DDT, hexachlorocyclohexanes and polycyclic aromatic hydrocarbons in an ice core from Mt. Everest, central Himalayas, China, Atmos. Environ., 42, 6699-6709, 2008.

Wang, X., Gong, P., Zhang, Q., and Yao, T.: Impact of climate fluctuations on deposition of DDT and hexachlorocyclohexane in mountain glaciers: Evidence from ice core records, Environ. Pollut., 158, 375-380, 2010.

Wania, F.: Modelling the behaviour of non-polar organic chemicals in an ageing snow pack, Chemosphere, 35, 2345-2363, 1997.

Wania, F.: The significance of long-range transport of persistent organic pollutants by migratory animals. 3/98, WECC, Toronto, ON, Canada, 1998.

Wania, F.: Assessing the potential of persistent organic chemicals for long-range transport and accumulation in polar regions, 37, 1344-1351, 2003.

Wania, F. and Dugani, C. B.: Assessing the long-range transport potential of polybrominated diphenyl ethers: A comparison of four multimedia models, Environ. Toxicol. Chem., 22, 1252-1261, 2003.

Wania, F. and Mackay, D.: Global fractionation and cold condensation of low volatility organochlorine compounds in polar regions, Ambio, 22, 10-18, 1993.
Wania, F. and Westgate, J. N.: On the mechanism of mountain coldtrapping of organic chemicals, Environ. Sci. Technol., 42, 90929098, 2008.

Wania, F., Pacyna, J., and Mackay, D.: Global fate of persistent organic pollutants, Toxicol. Environ. Chem., 66, 81-89, 1998a.

Wania, F., Hoff, J. T., Jia, C. Q., and Mackay, D.: The effects of snow and ice on the environmental behaviour of hydrophobic organic chemicals, Environ. Pollut., 102, 25-41, 1998 b.

Wania, F., Mackay, D., and Hoff, J. T.: The importance of snow scavenging of polycyclic biphenyl and polycyclic aromatic hydrocarbon vapors, Environ. Sci. Technol., 33, 195-197, 1999a.

Wania, F., Semkin, R., Hoff, J., and Mackay D.: Modelling the fate of non-polar organic chemicals during the melting of an Arctic snowpack, Hydrol. Proc., 13/14-15, 2245-2256, 1999b.

Weber, J., Kurkova, R., Klánová, J., Klán, P., and Halsall, C. J.: Photolytic degradation of methyl-parathion and fenitrothion in ice and water: Implications for cold environments, Environ. Pollut., 157, 3308-3313, 2009.

Wong, F. L., Jantunen, L. M., Pućko, M., Papakyriakou, T., Staebler, R. M., Stern, G. A., and Bidleman, T. F.: Air-water exchange of anothropogenic and natural organohalogens on International Polar Year (IPY) expeditions in the Canadian Arctic, Environ. Sci. Technol., 45, 876-881, 2011.

Xiao, H., Li, N., and Wania, F.: Compilation, evaluation, and selection of physical-chemical property data for $\alpha-, \beta$ - and $\gamma$ hexachlorocyclohexane, J. Chem. Eng. Data, 49, 173-185, 2004.

Young, C. J., Furdui, V. I., Franklin, J., Koerner, R. M., Muir, D. C. G., and Mabury, S. A.: Perfluorinated acids in Arctic snow: new evidence for atmospheric formation, Environ. Sci. Technol., 41, 3455-3461, 2007.

Zabik, J. and Seiber, J. N.: Atmospheric transport of organophosphate pesticides from California's Central Valley to the Sierra Nevada Mountains, J. Environ. Quality, 22, 80-90, 1993.

Zhang, X., Naidu, A. S., Kelley, J.J., Jewett, S. C., Dasher, D., and Duffy, L. K.: Baseline concentrations of total mercury and methylmercury in salmon returning via the Bering Sea (19992000), Mar. Poll. Bull., 42, 933-997, 2001.

Zhao, L. T. and Gray, D. M.: Estimating snowmelt infiltration into frozen soils, Hydrol. Proc., 13, 1827-1842, 1999. 